\title{
Synthesis of conformationally constrained dipeptide mimetics with azabicyclo[4,3,0]nonanone and azabicyclo[5,3,0]decanone scaffolds
}

\author{
Wanlin Xi, Lei Du, Liping Zhang and Haiying Sun* \\ Jiangsu Key Laboratory of Drug Design and Optimization, Department of Medicinal Chemistry, School of \\ Pharmacy, China Pharmaceutical University, Nanjing 21009, China
}

\author{
Corresponding Author \\ * E-mail: haiyings1969@cpu.edu.cn
}

\section{Supporting Information}

\author{
Table of Contents
}

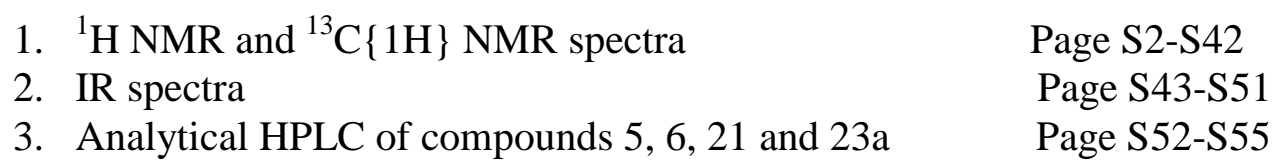




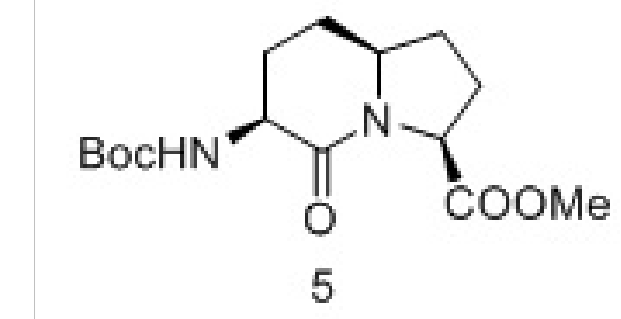

5
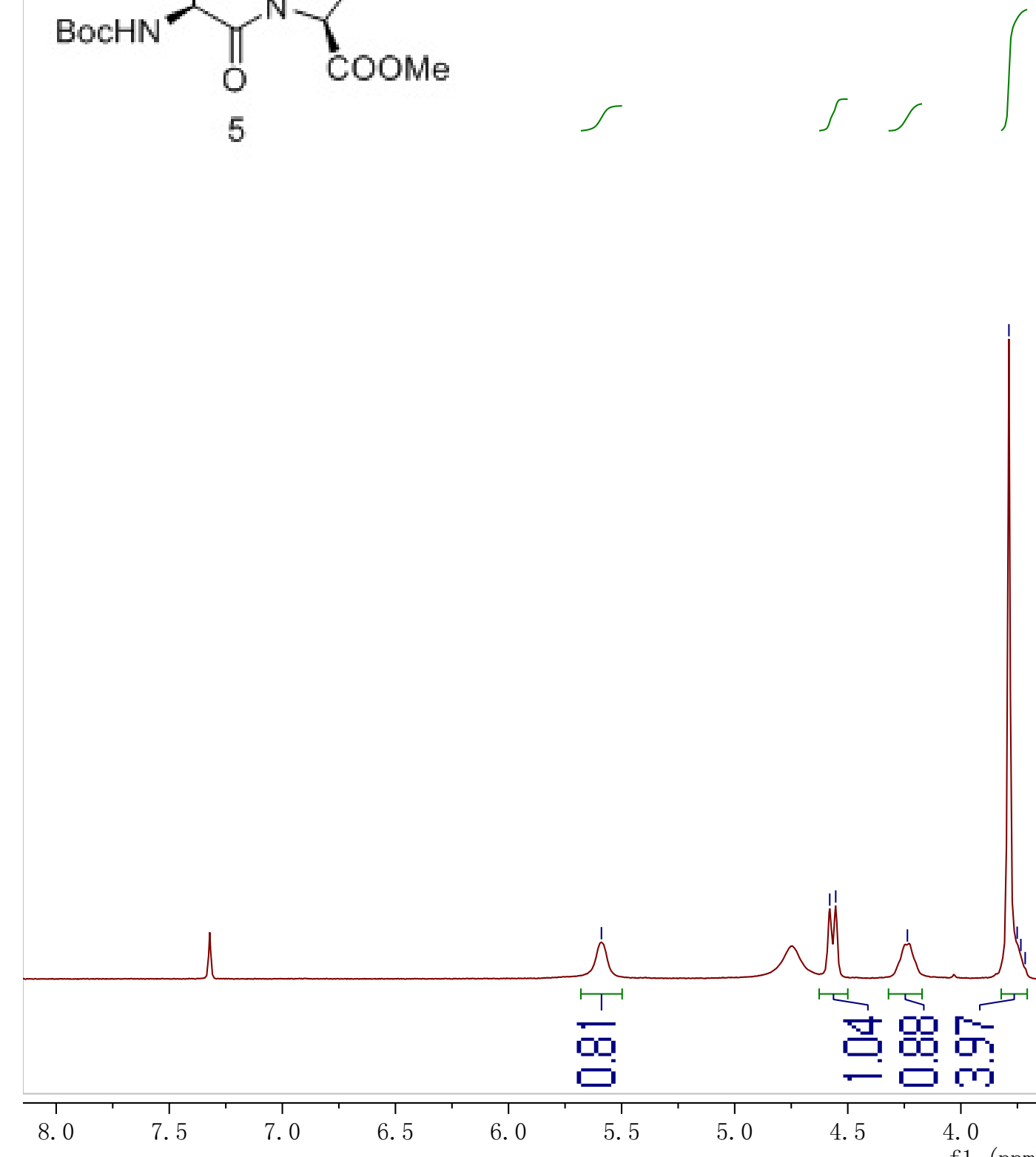

5

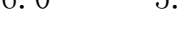


xw1-21-66-201906112. fid $\risingdotseq$ 5-C-NMR CDC13 75MHz

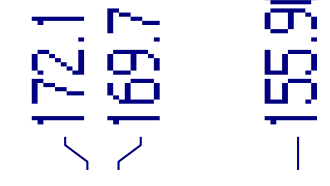

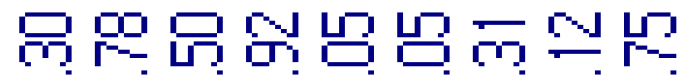

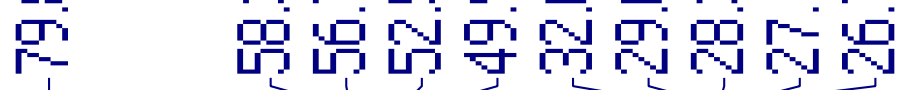

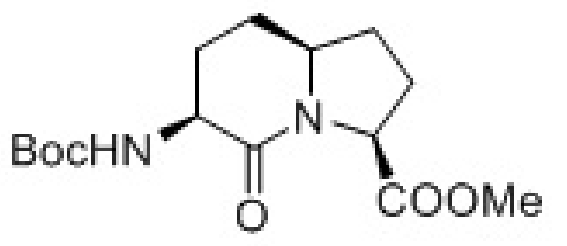

5

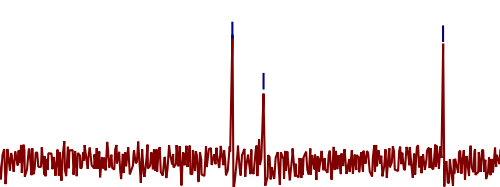



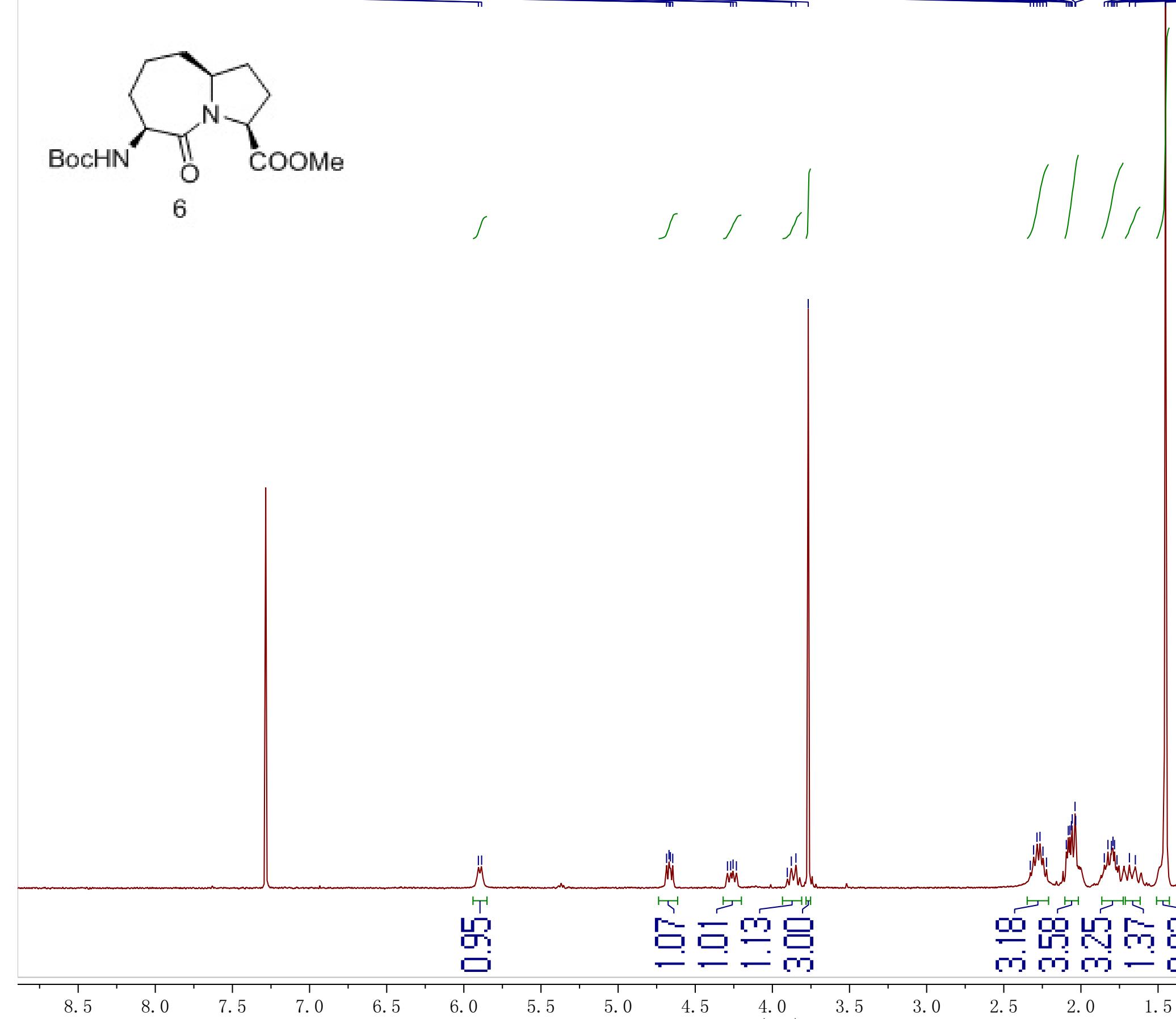

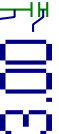

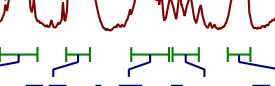
00 (ד) 


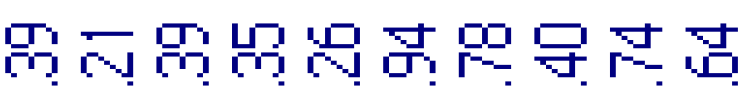

员思比药

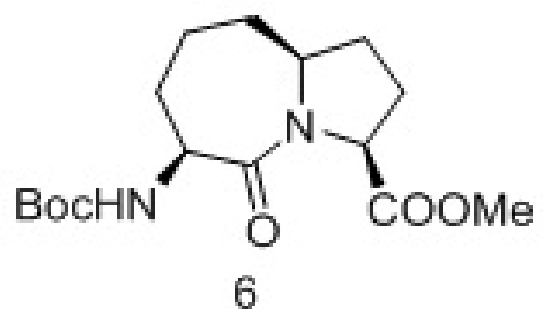

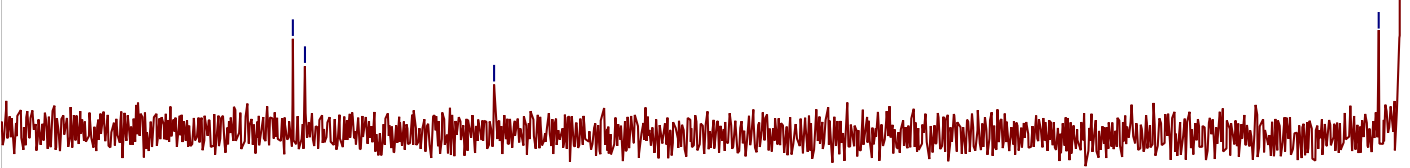




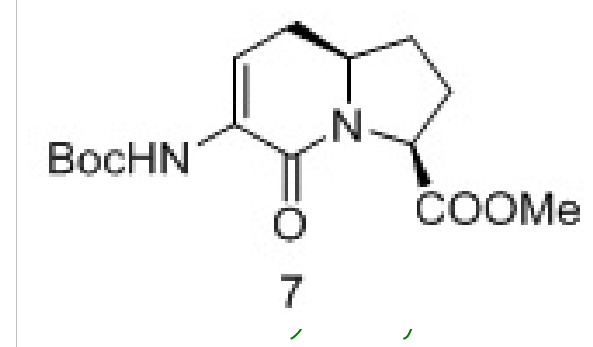

-

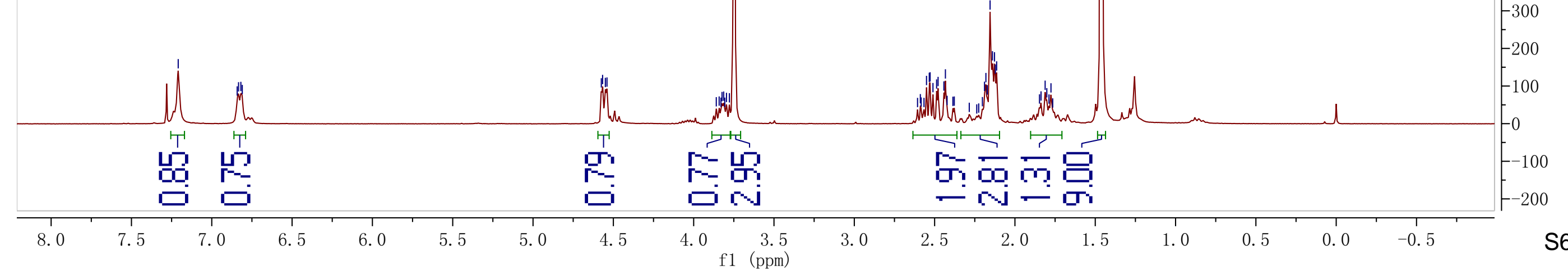




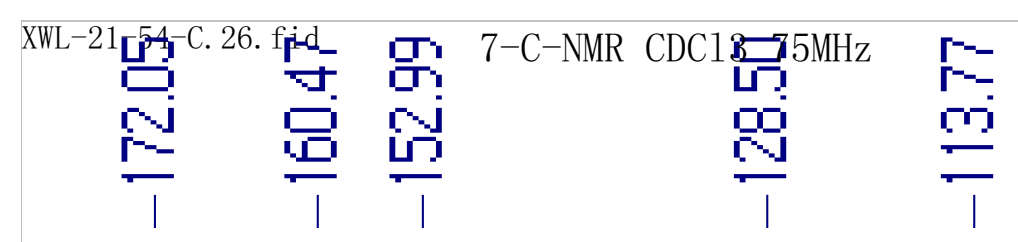

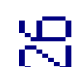

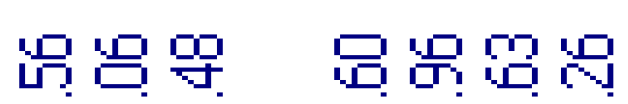

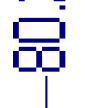

ज为

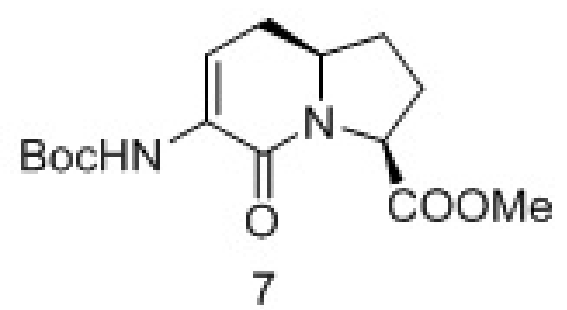




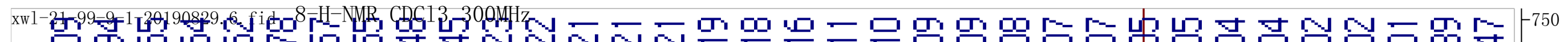
맘

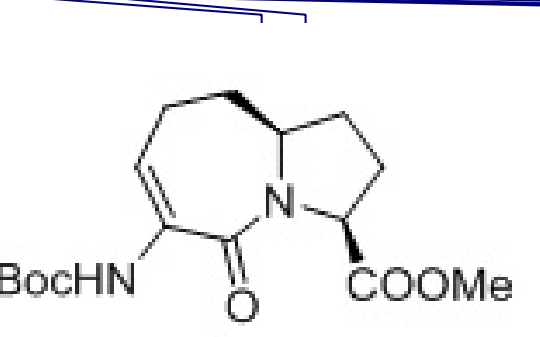

8
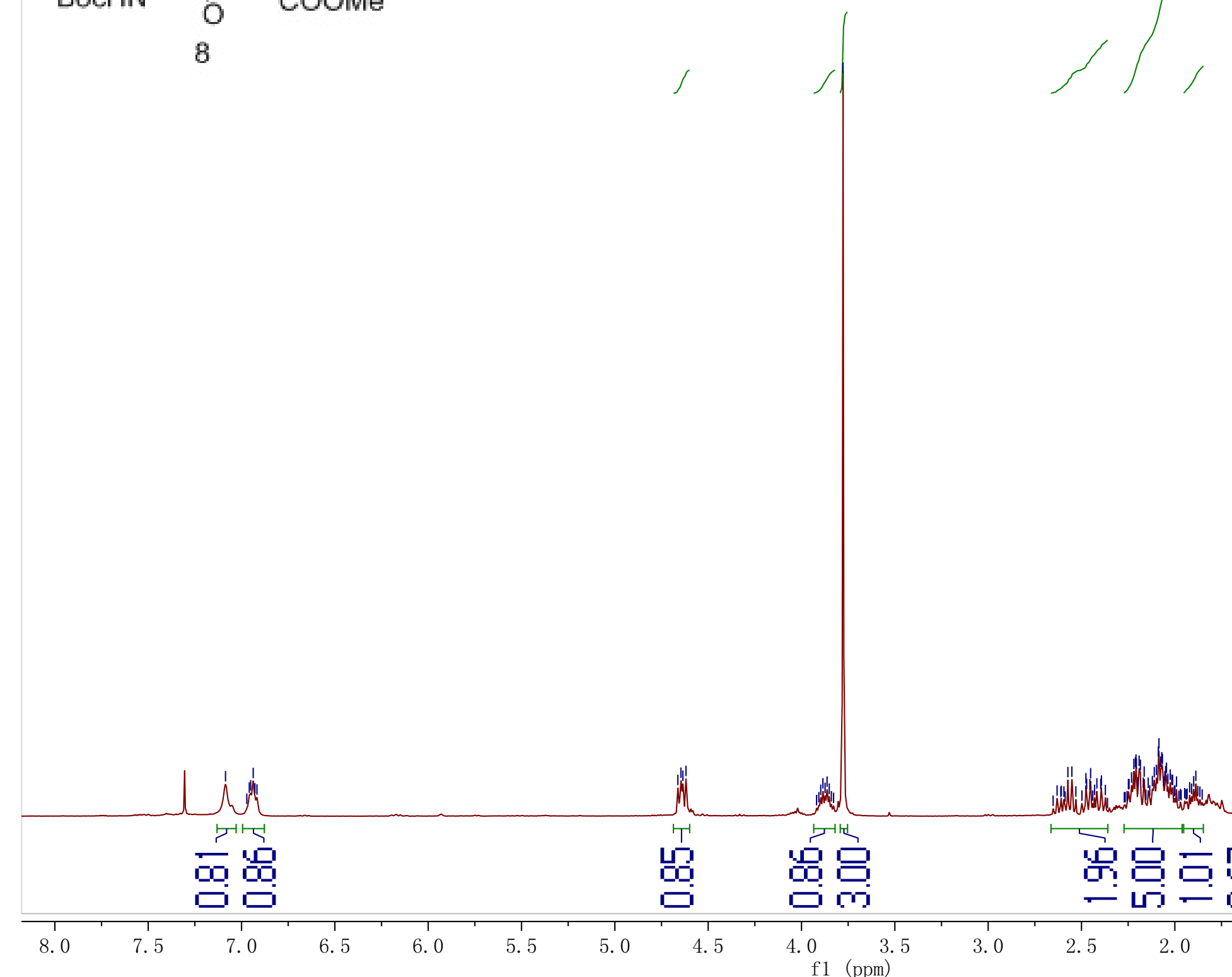

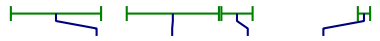


xw1-21-99-9-c-2019829.

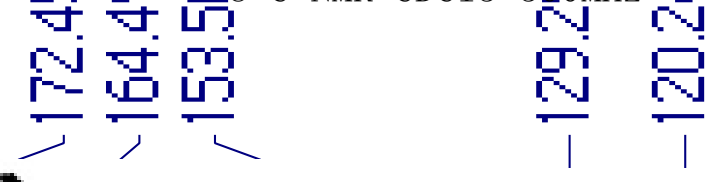

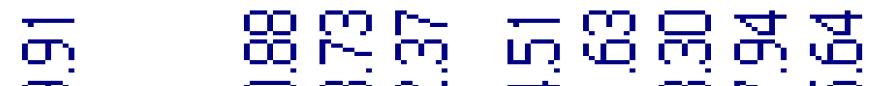

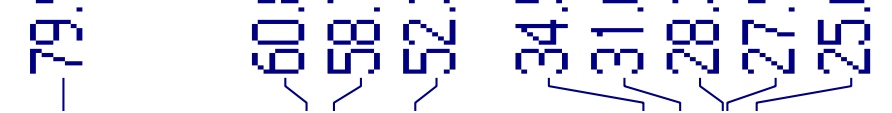

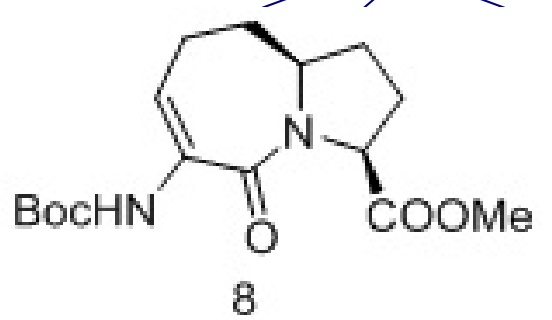




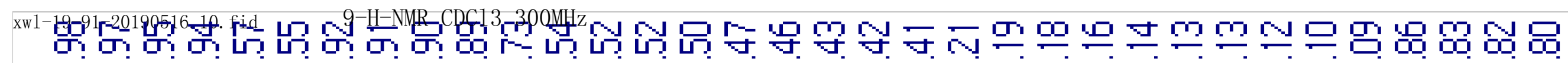

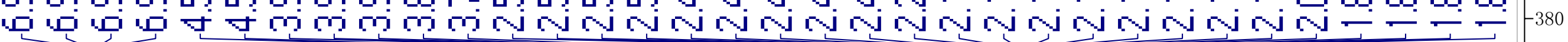<smiles>CC(=O)OC1CCC2CC=C(Br)C(=O)N21</smiles>
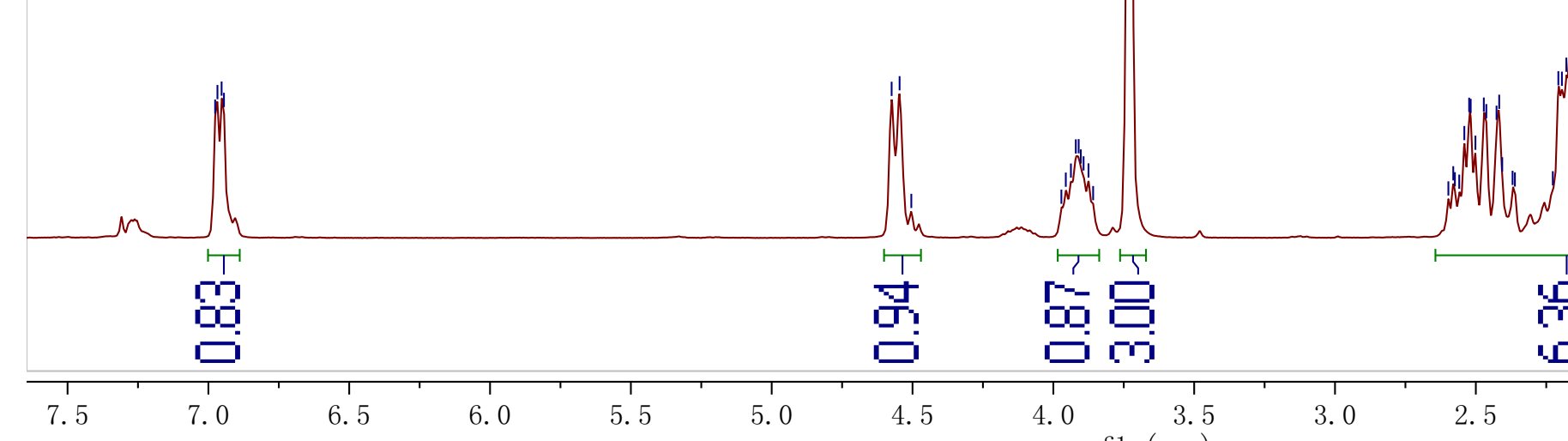


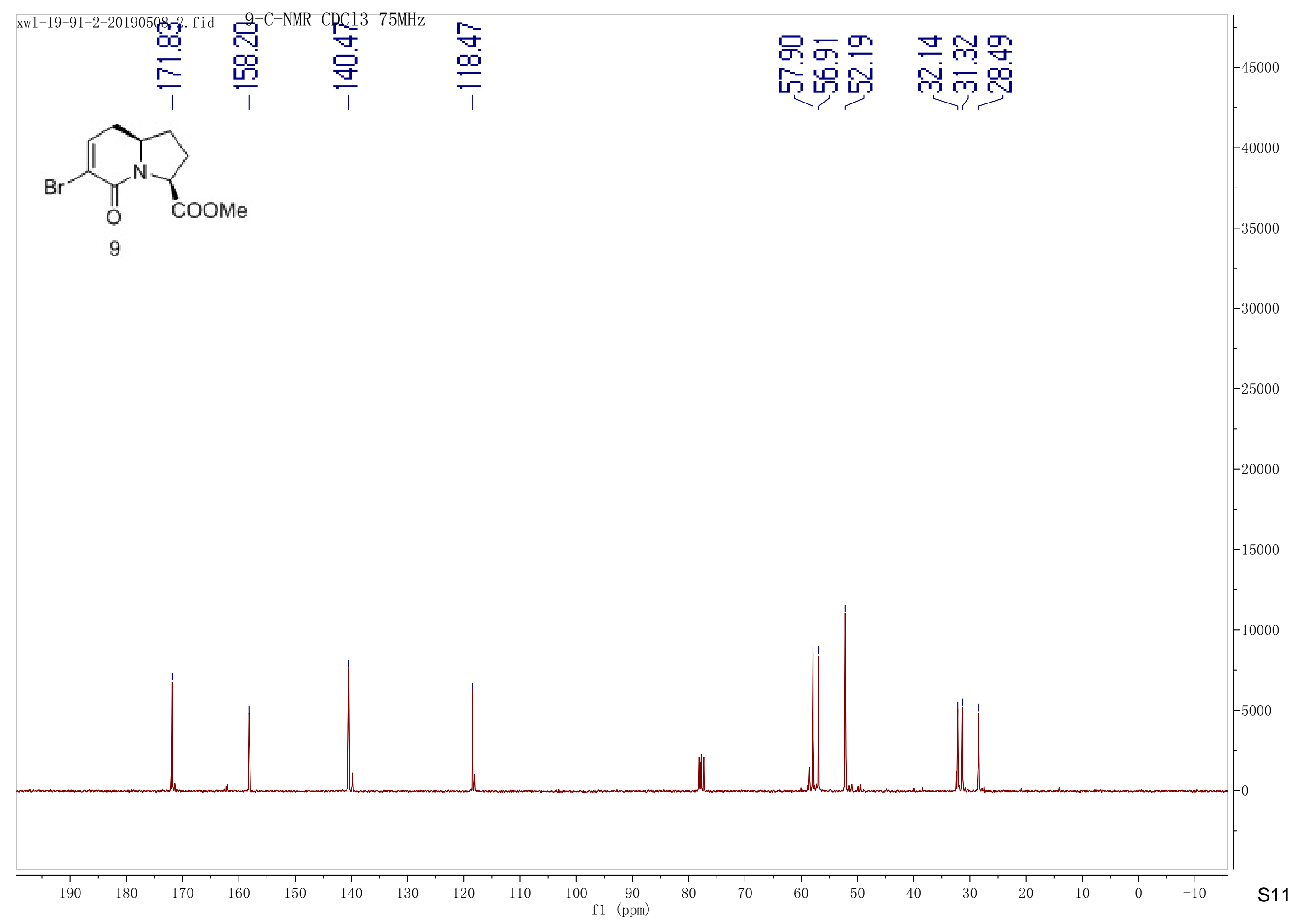


10-H-NMR CDC13 300MHz

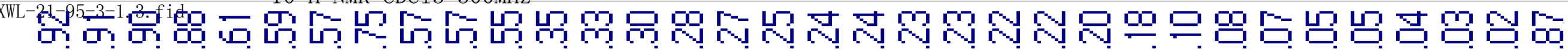

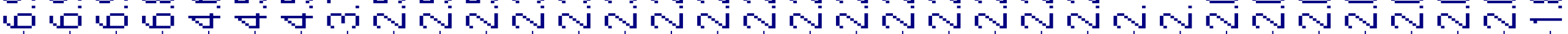
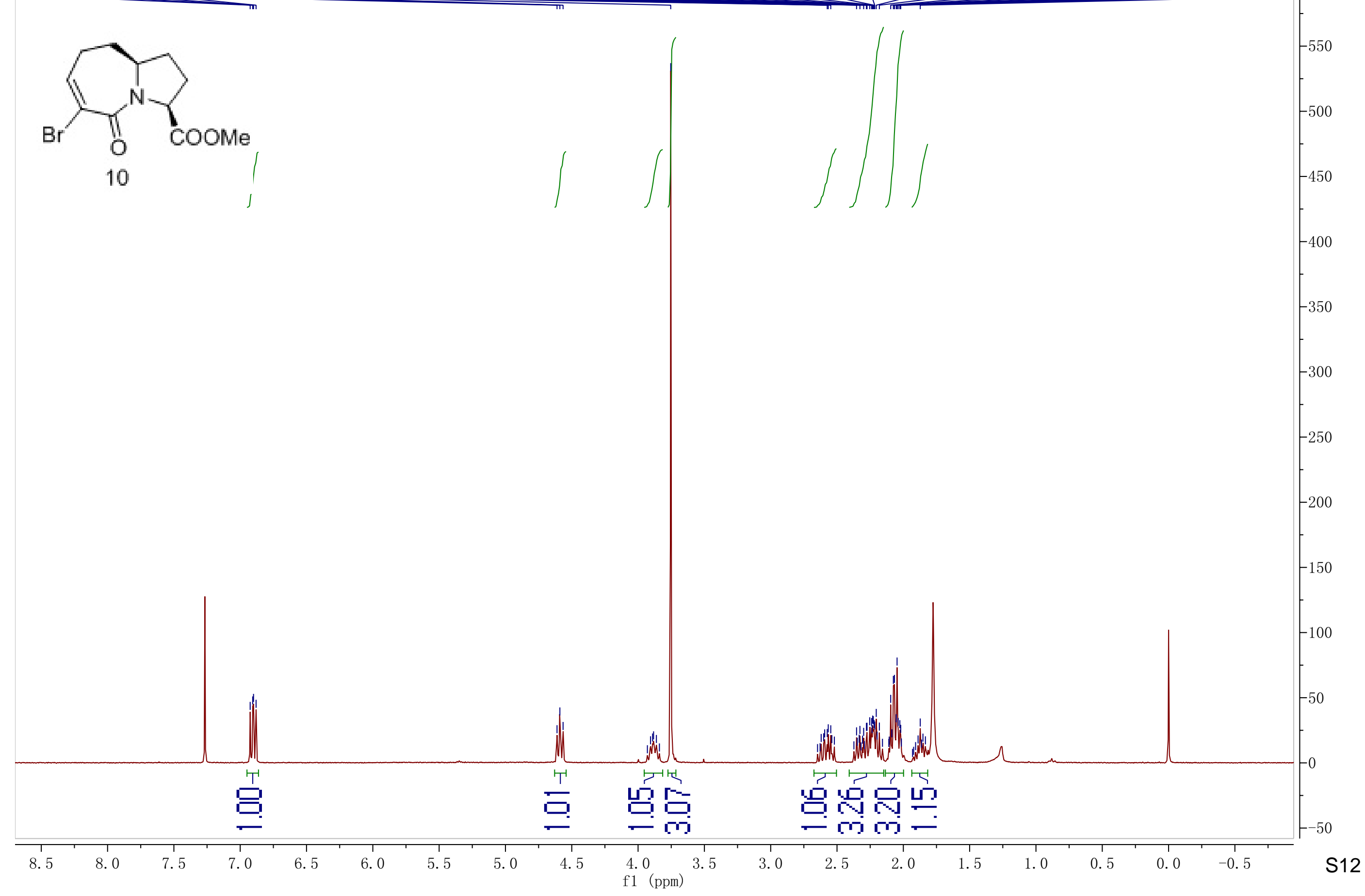


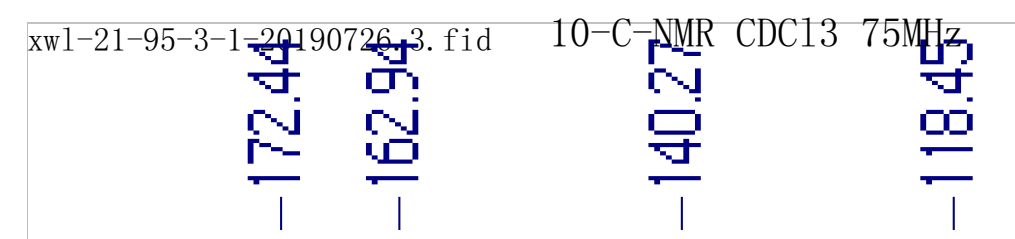

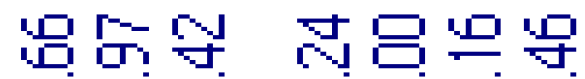

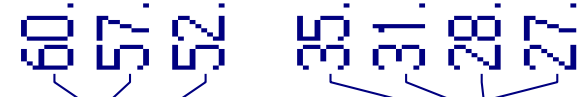

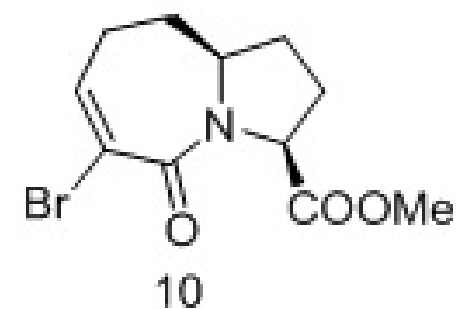




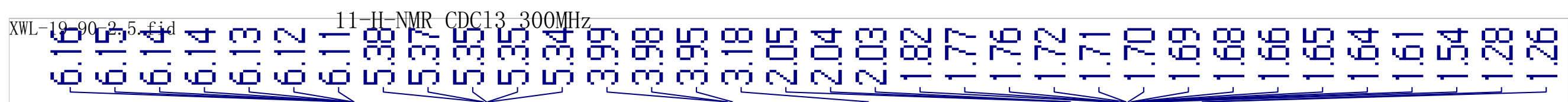

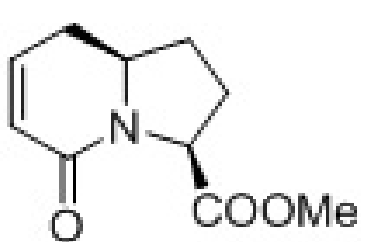

11
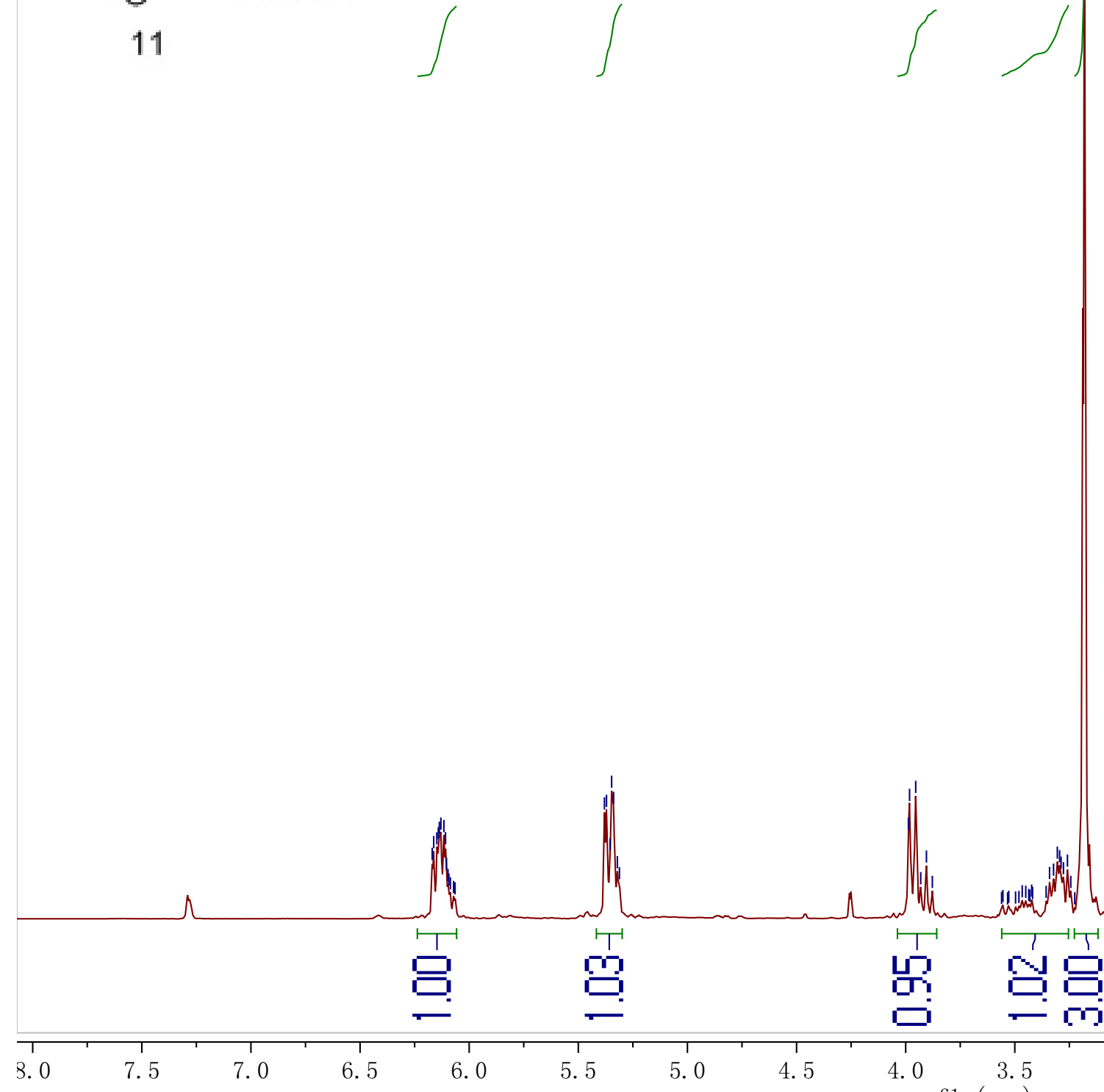

f1 (ppm)

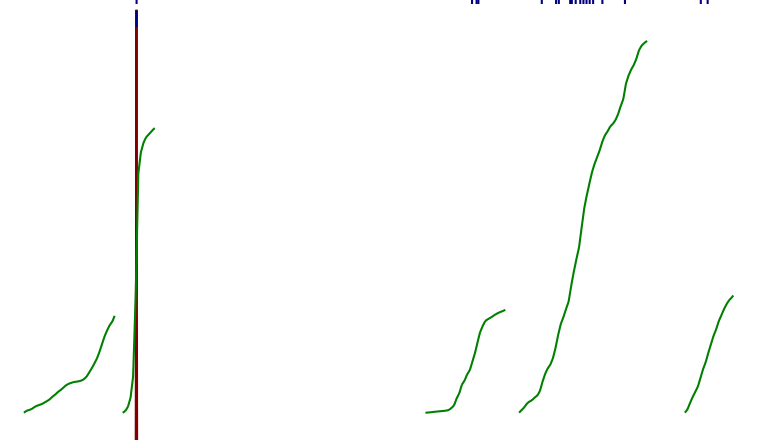




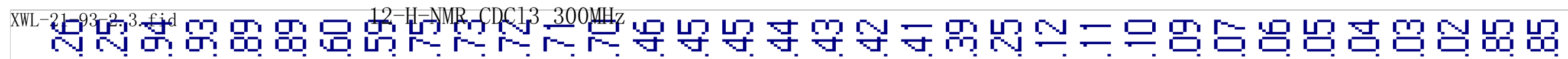

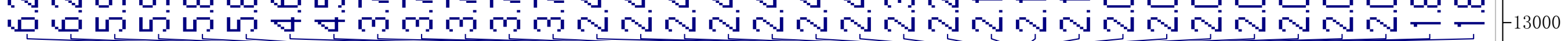

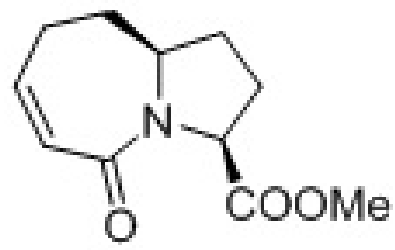

12

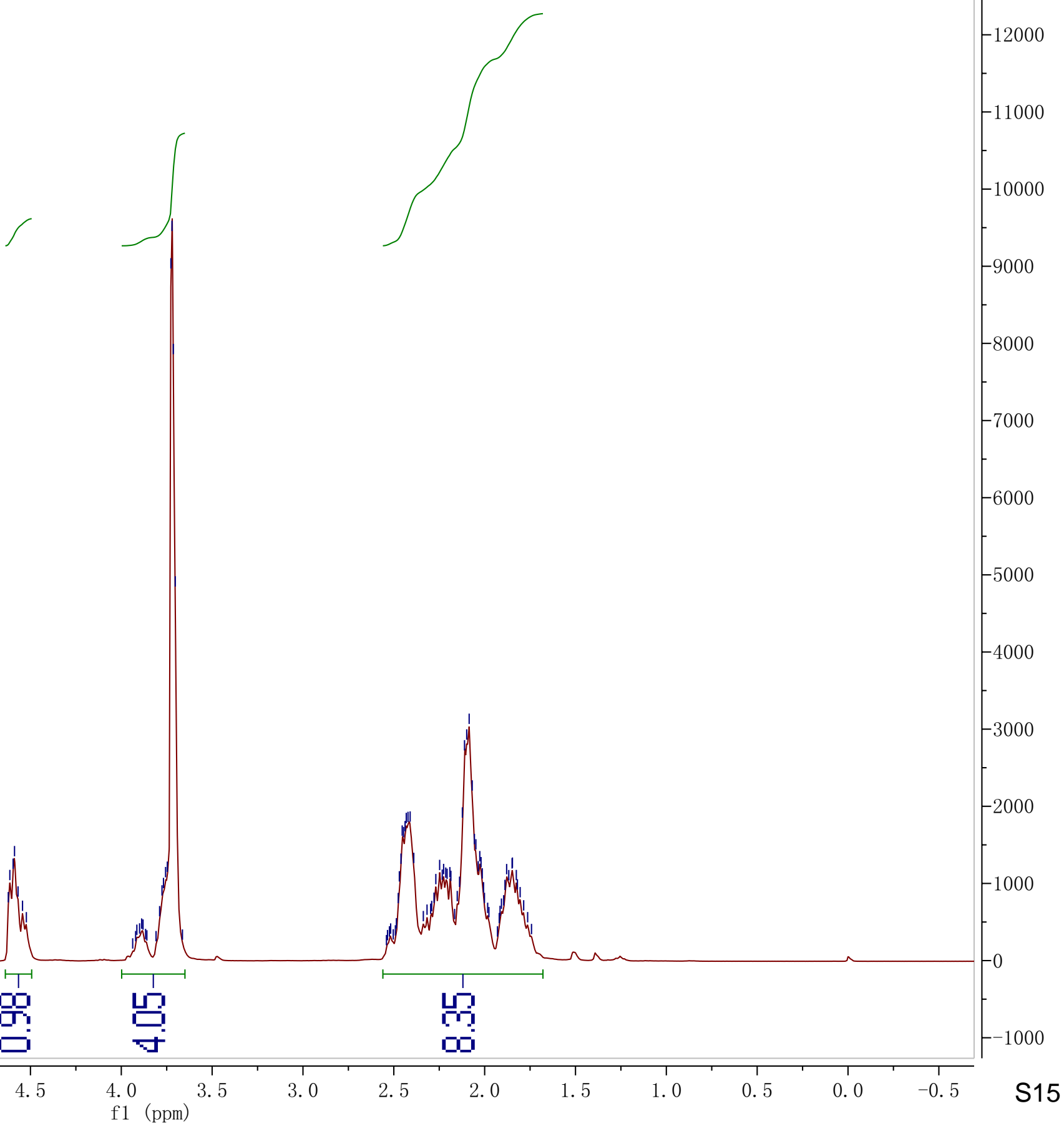


$\mathrm{XWL}-12-\beta 8-1,32 \mathrm{fid}-17-\mathrm{H}-\mathrm{NMR} \mathrm{CDCl} 3 \quad 300 \mathrm{MHz}$

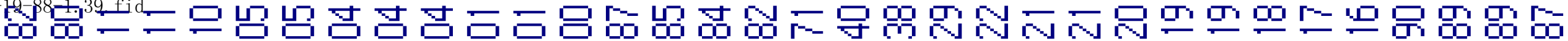

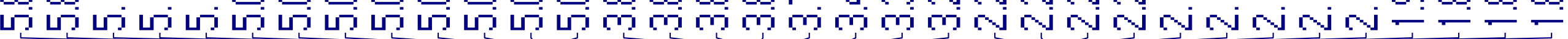

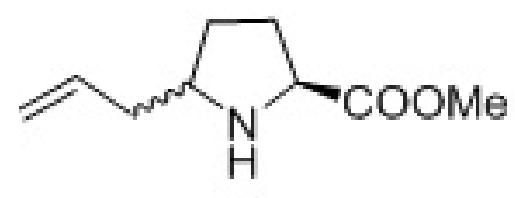

17
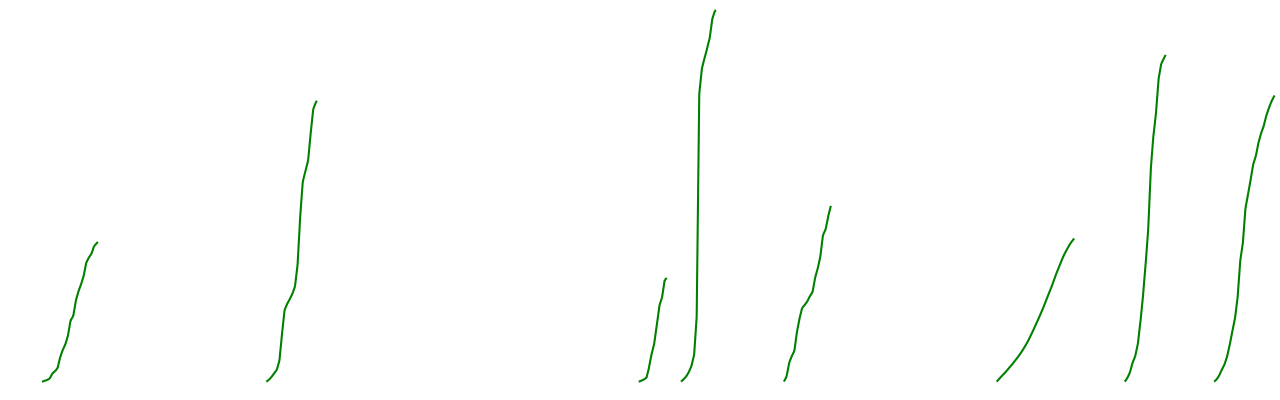

\begin{tabular}{l}
-28000 \\
-26000 \\
-24000 \\
-22000 \\
-18000 \\
-14000 \\
-12000 \\
-10000 \\
-8000 \\
-6000 \\
-4000 \\
\hline-2000 \\
\hline
\end{tabular}

f1 (ppm)

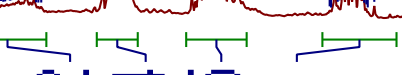

C. 대 0 


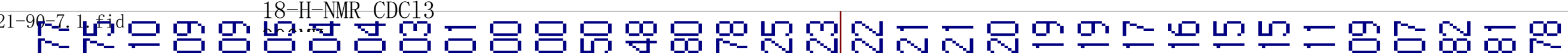

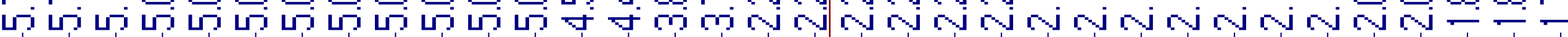

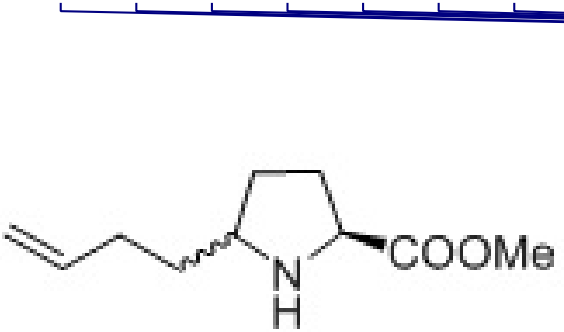

18




문

ㅁivi

18-C-NMR CDCT =

6

क⿻ ㇒⿴囗十

플

少
늠

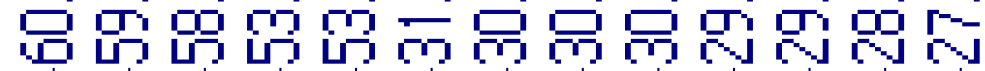

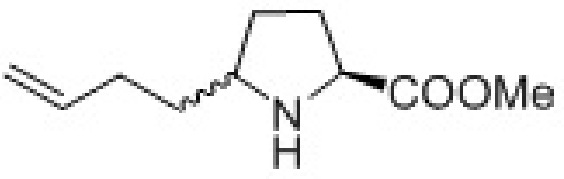

18

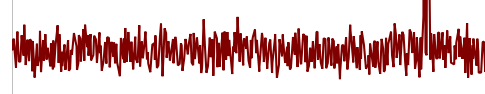




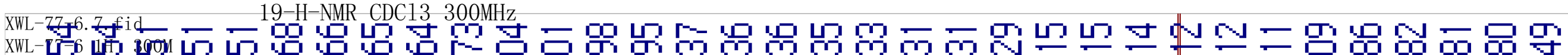

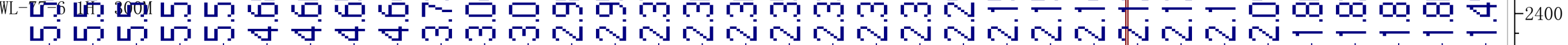

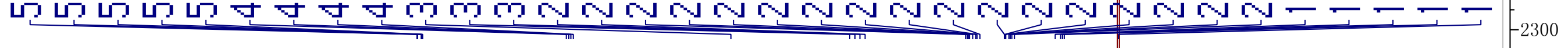<smiles>CC(=O)NC1=CCC[C@@H]2CC[C@@H](C(=O)OC(C)(C)C)N2C1=O</smiles>

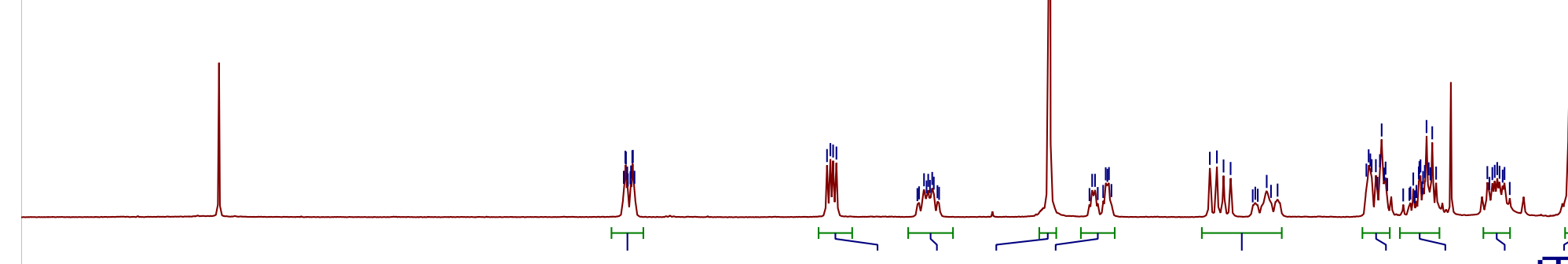

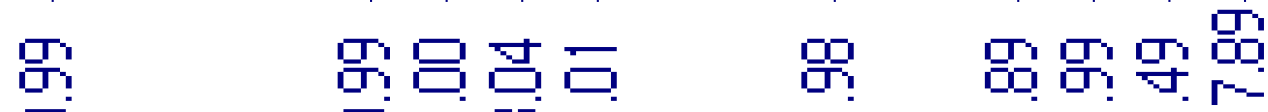

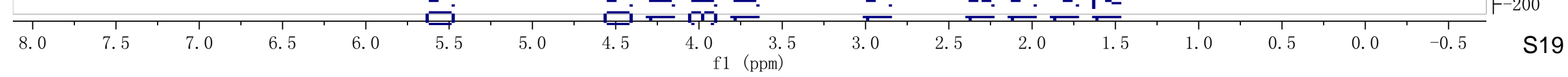


23-33-7C-2980Q-34. 2. fid

23-33-7C บำ

(5)

19-C-NMR CDC

$\frac{5}{1}$

믐

口Ti

$\overline{1}$

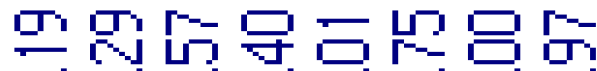

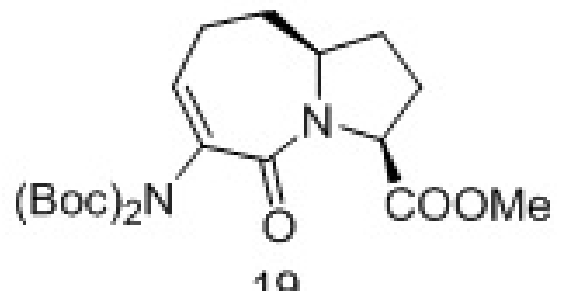

19

\section{邑 \\ 1)}




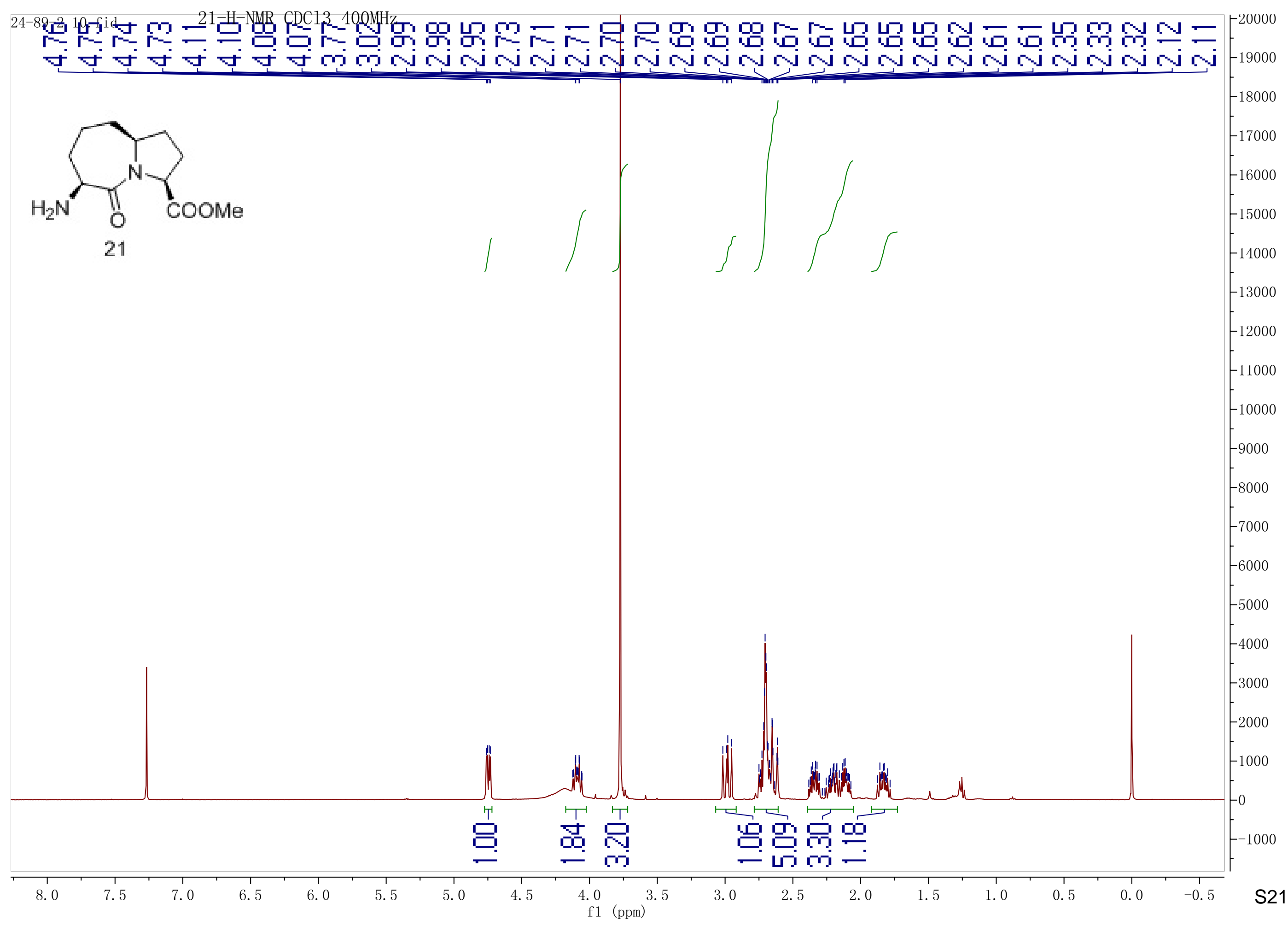




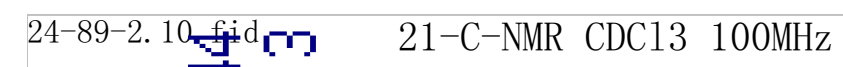
T-

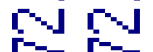

$+$

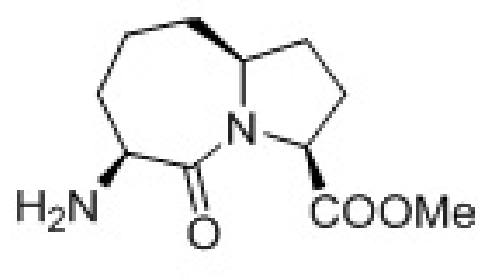

21

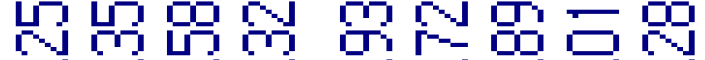

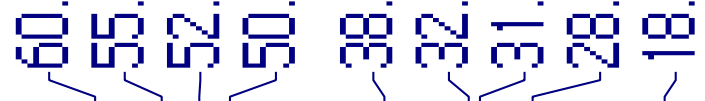




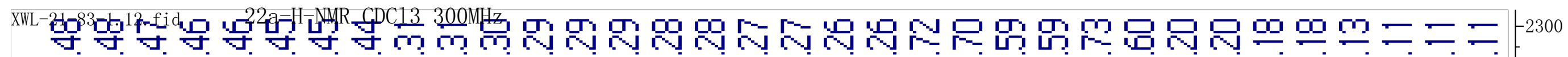

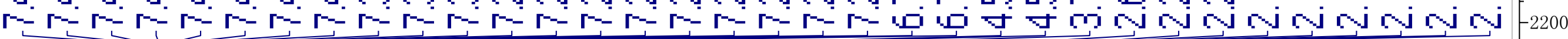
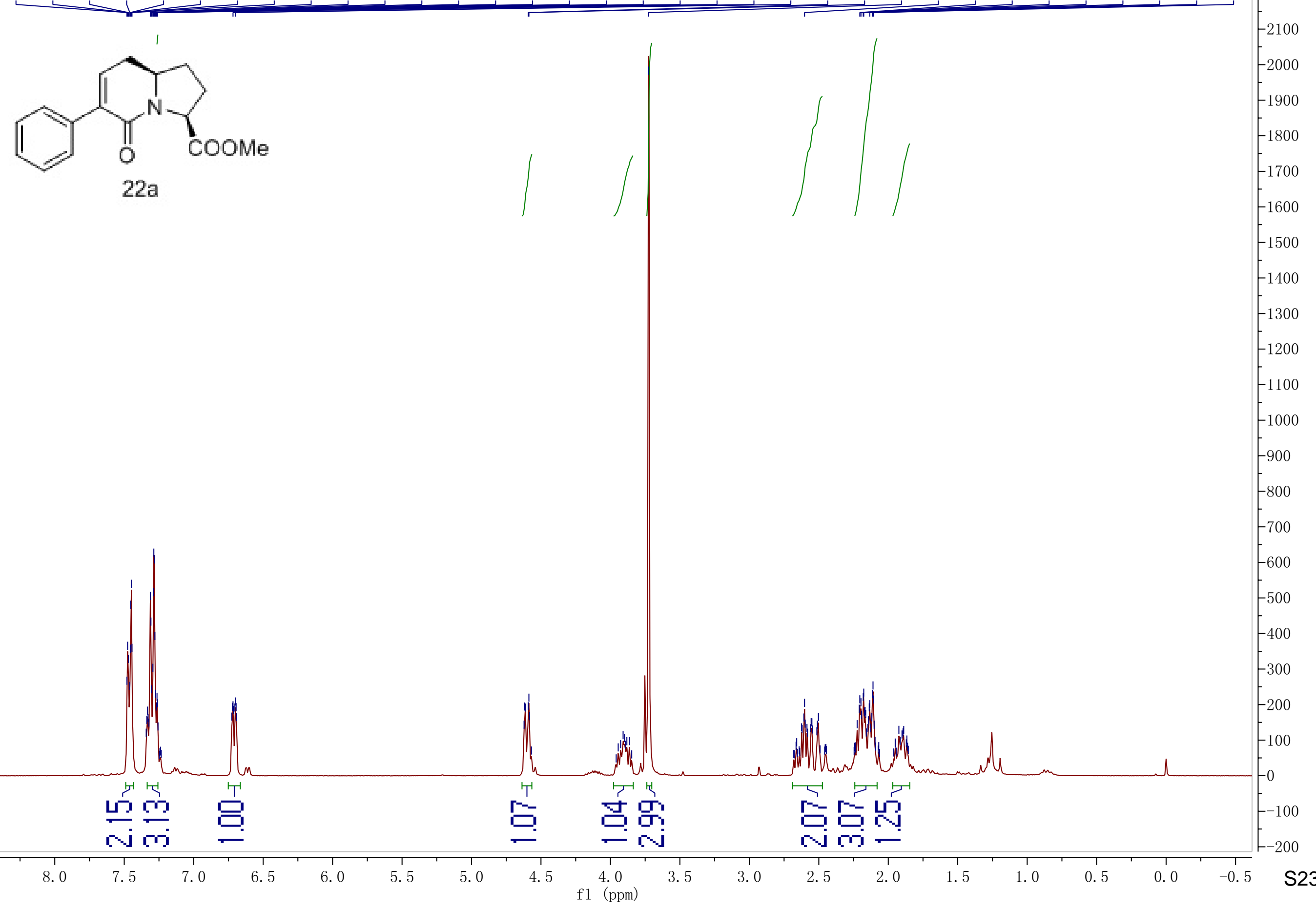


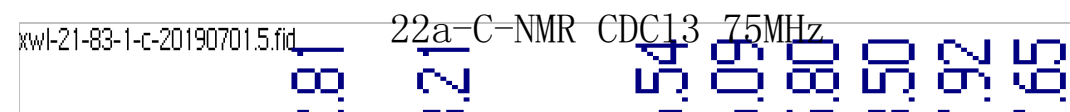

-

$\div \quad \frac{}{1}=$

wo

ris

祭熍

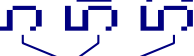

禺要
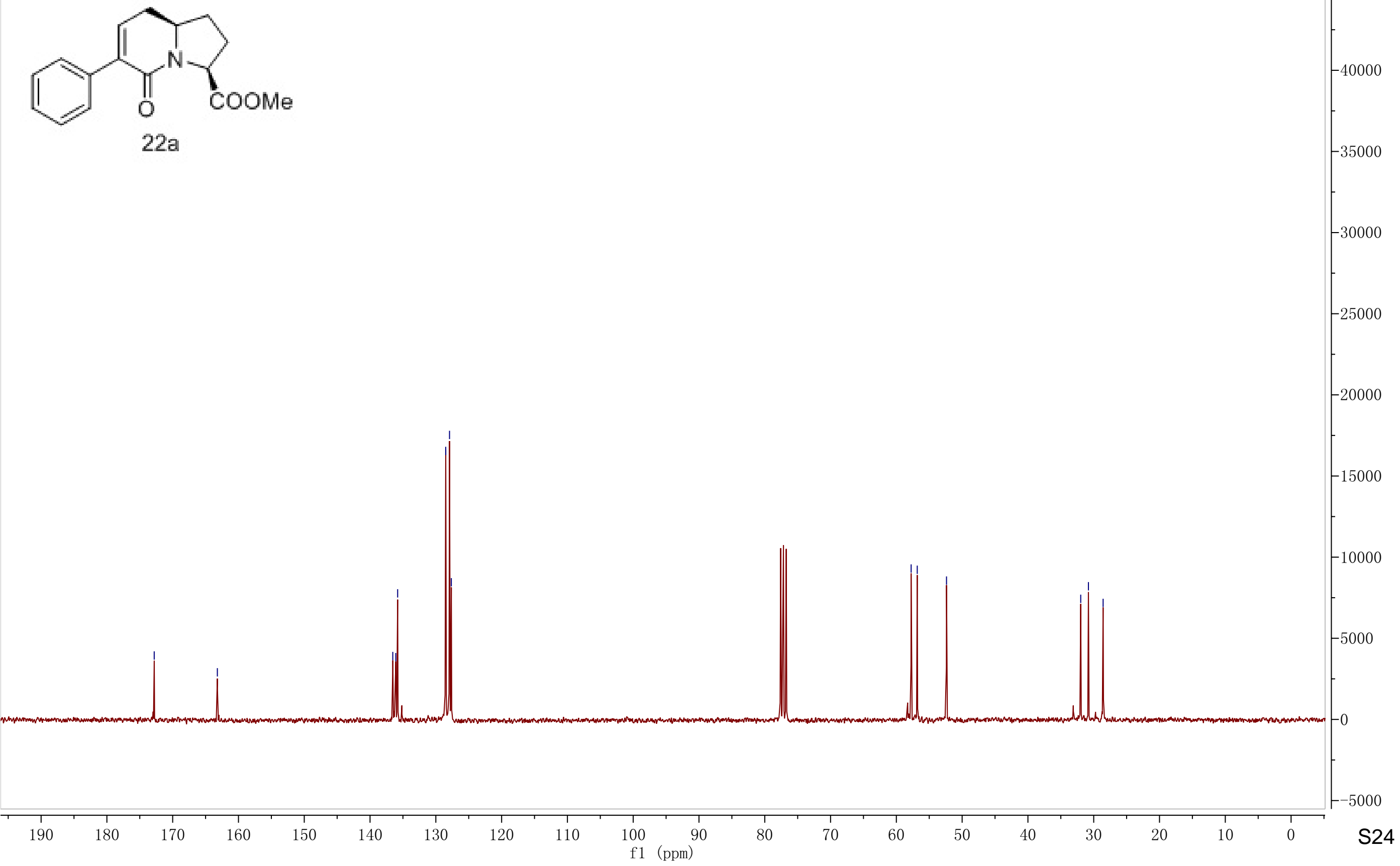


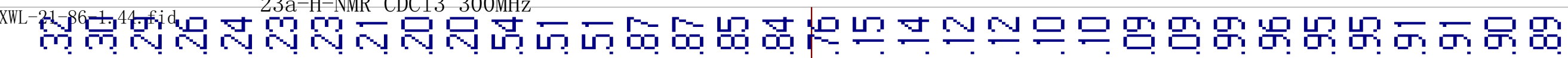

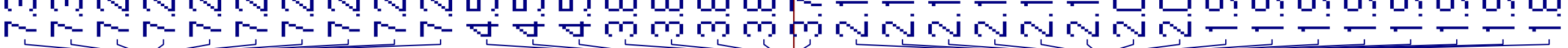

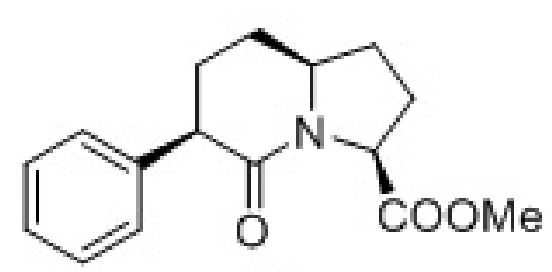

23a

J

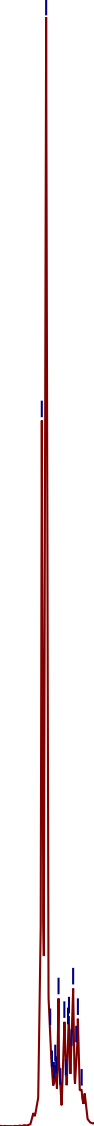

17

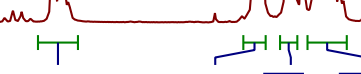

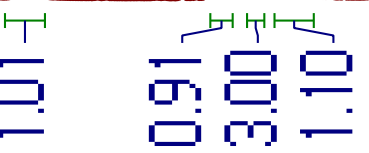
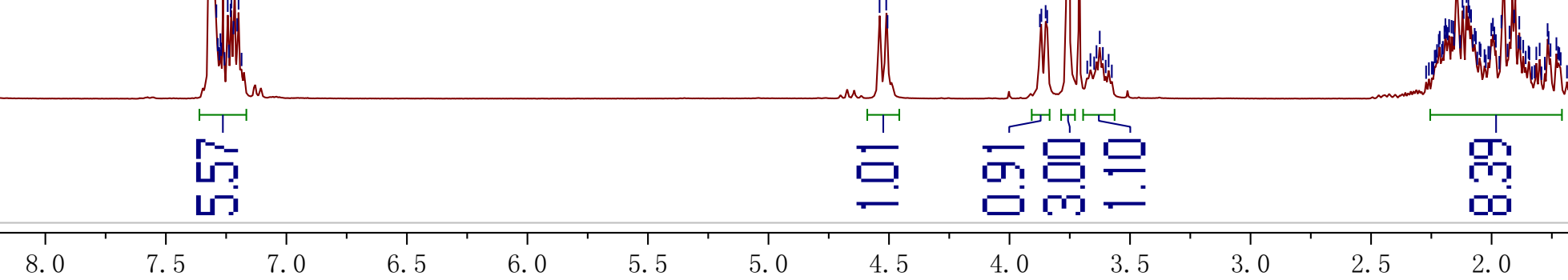

7.0

1


xw1-21-86-1-20190711. 6. fid 23a-C-NMR CDC13 75MHz

12

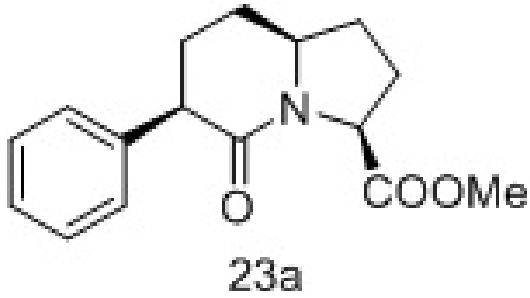

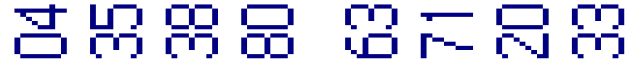

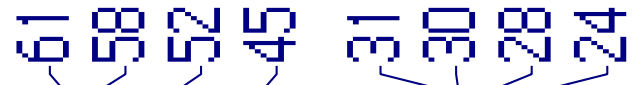




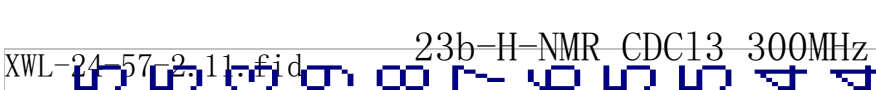

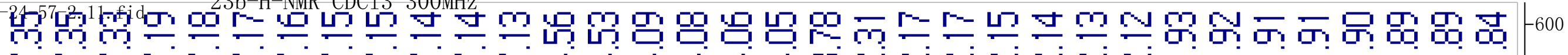

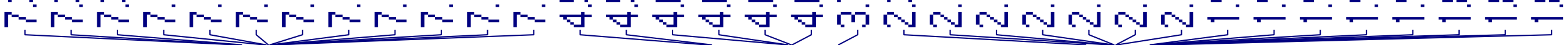

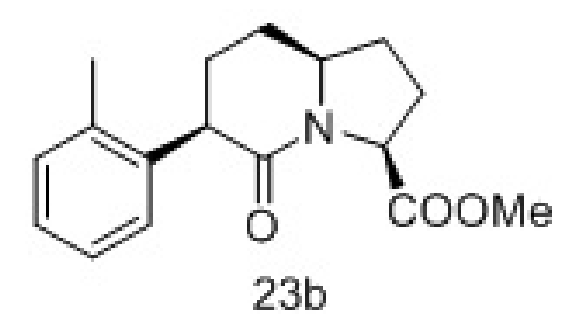

$23 b$

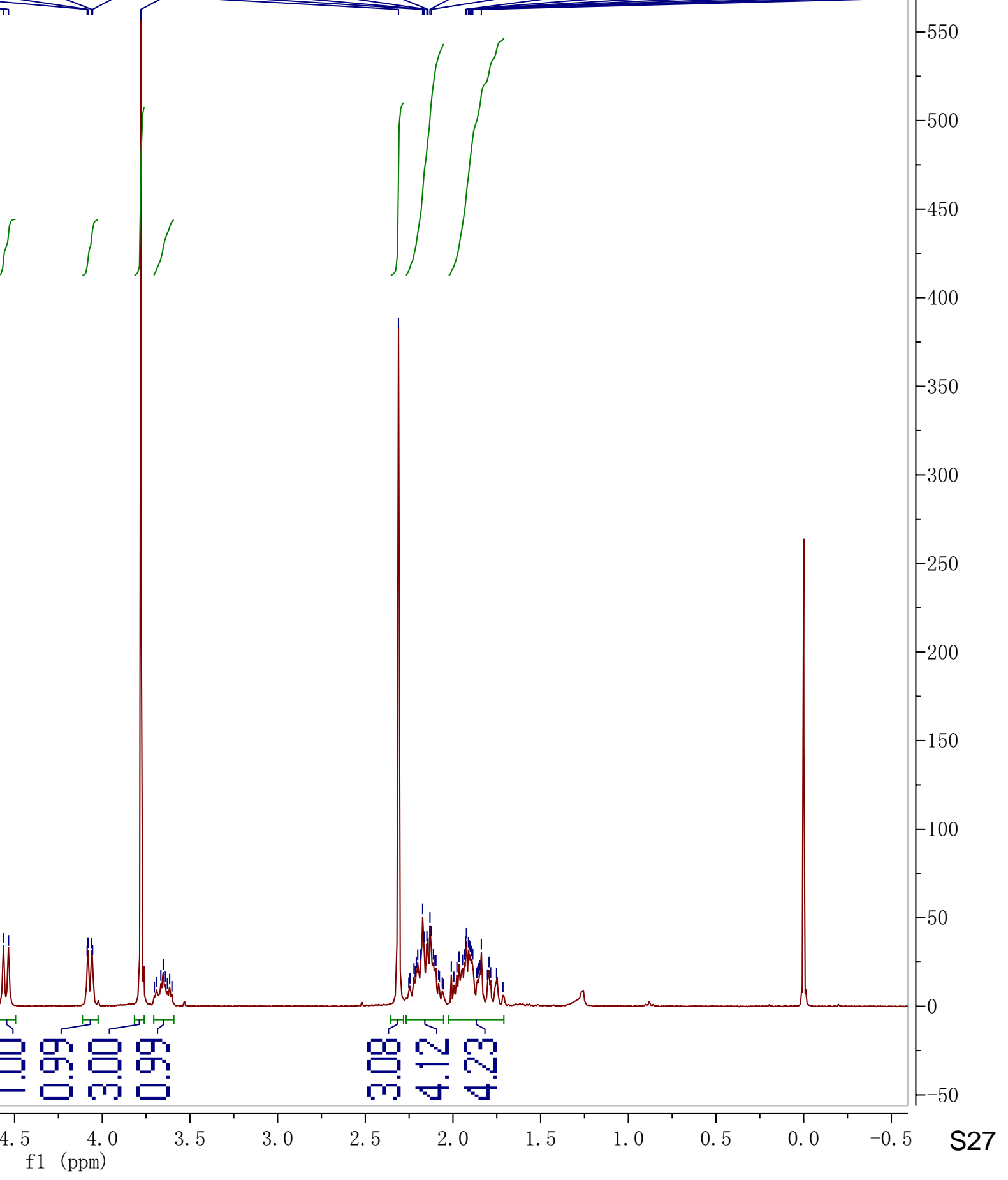


XWL-24-57-2-C.31. fid 23b-C-NMR CDC13 75MHz

$\mathrm{j}$ i

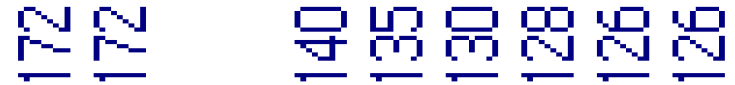

$=2$

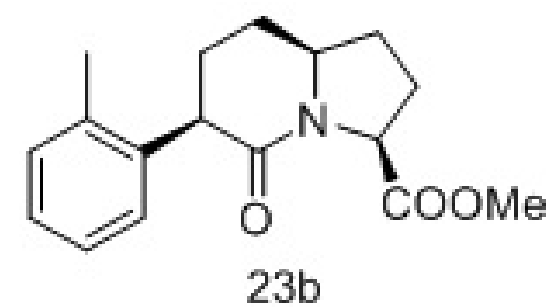

23b

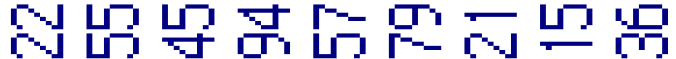

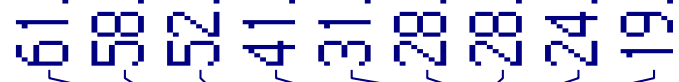
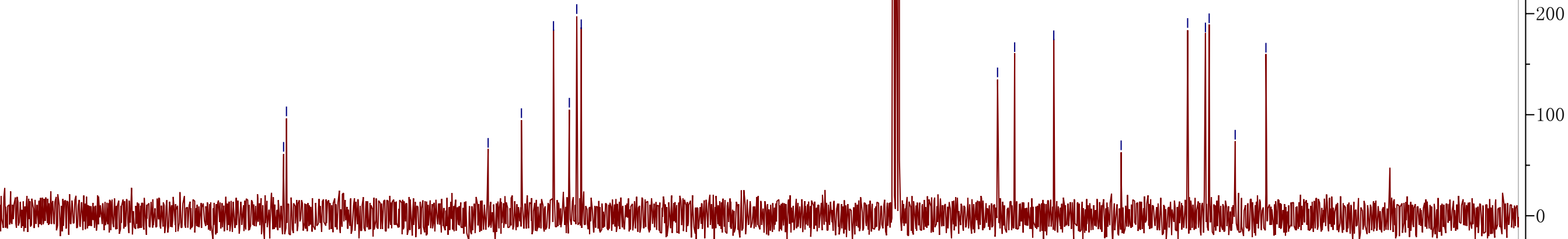

$200 \quad 190 \quad 180$

$170 \quad 160$

150

$140 \quad 130$

120

f1 $(\mathrm{ppm})$

$90 \quad 80$

$\begin{array}{ll}1 \\ 70 & 60\end{array}$

$50 \quad 40$

30

20
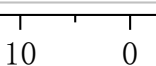

$-10$ 


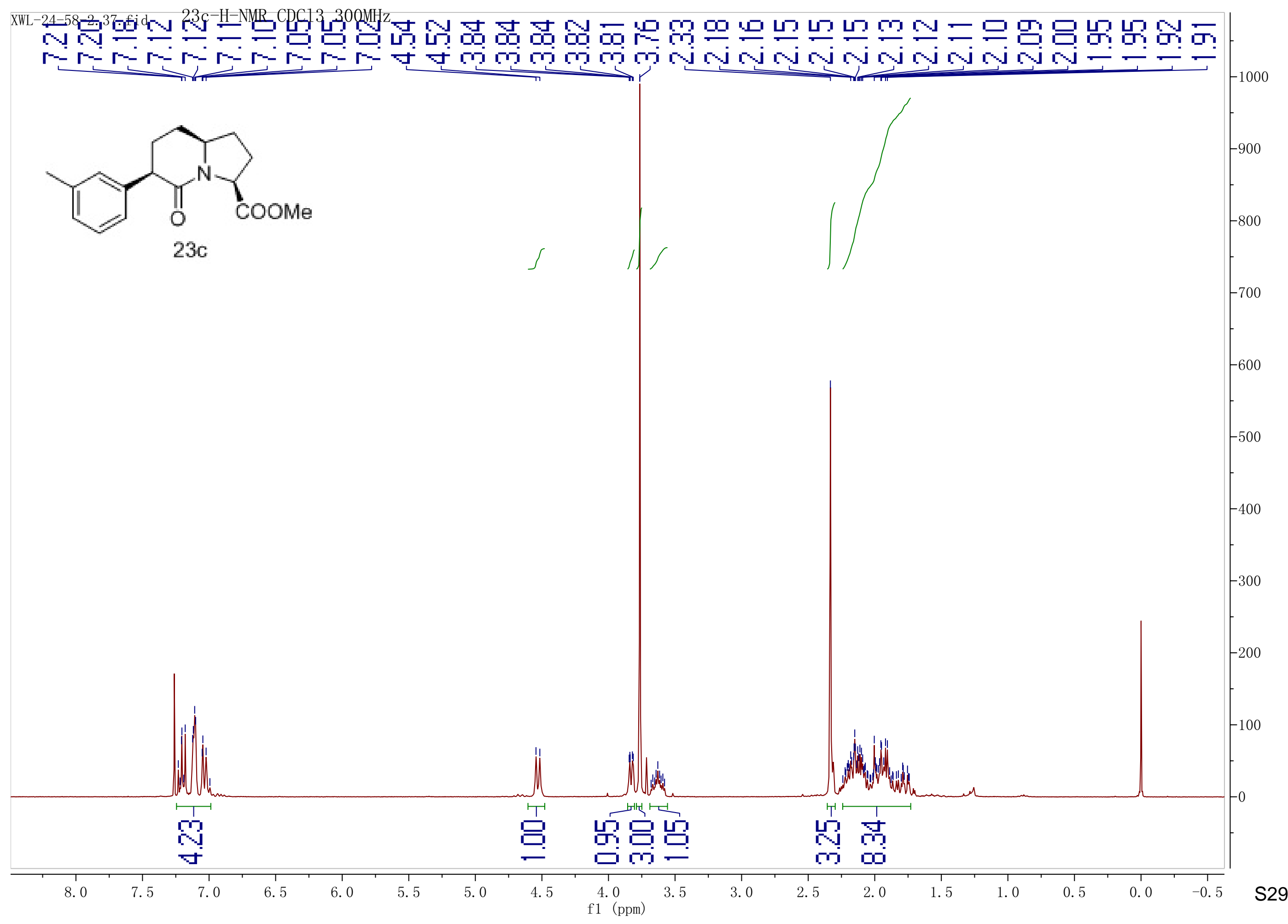




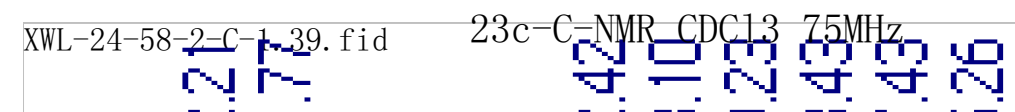

西

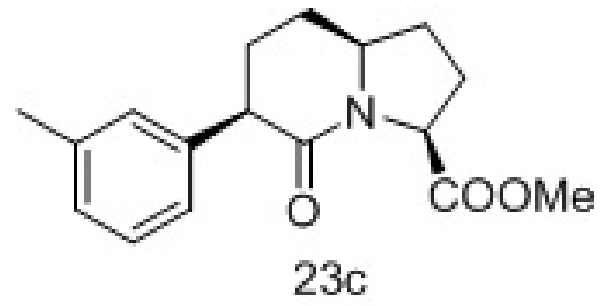

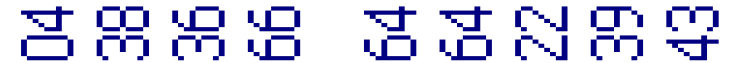

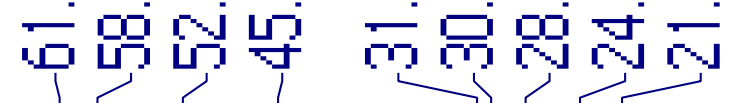




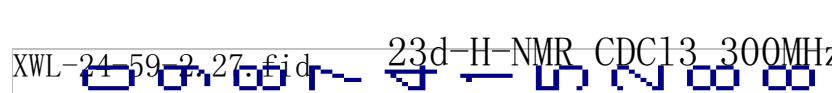

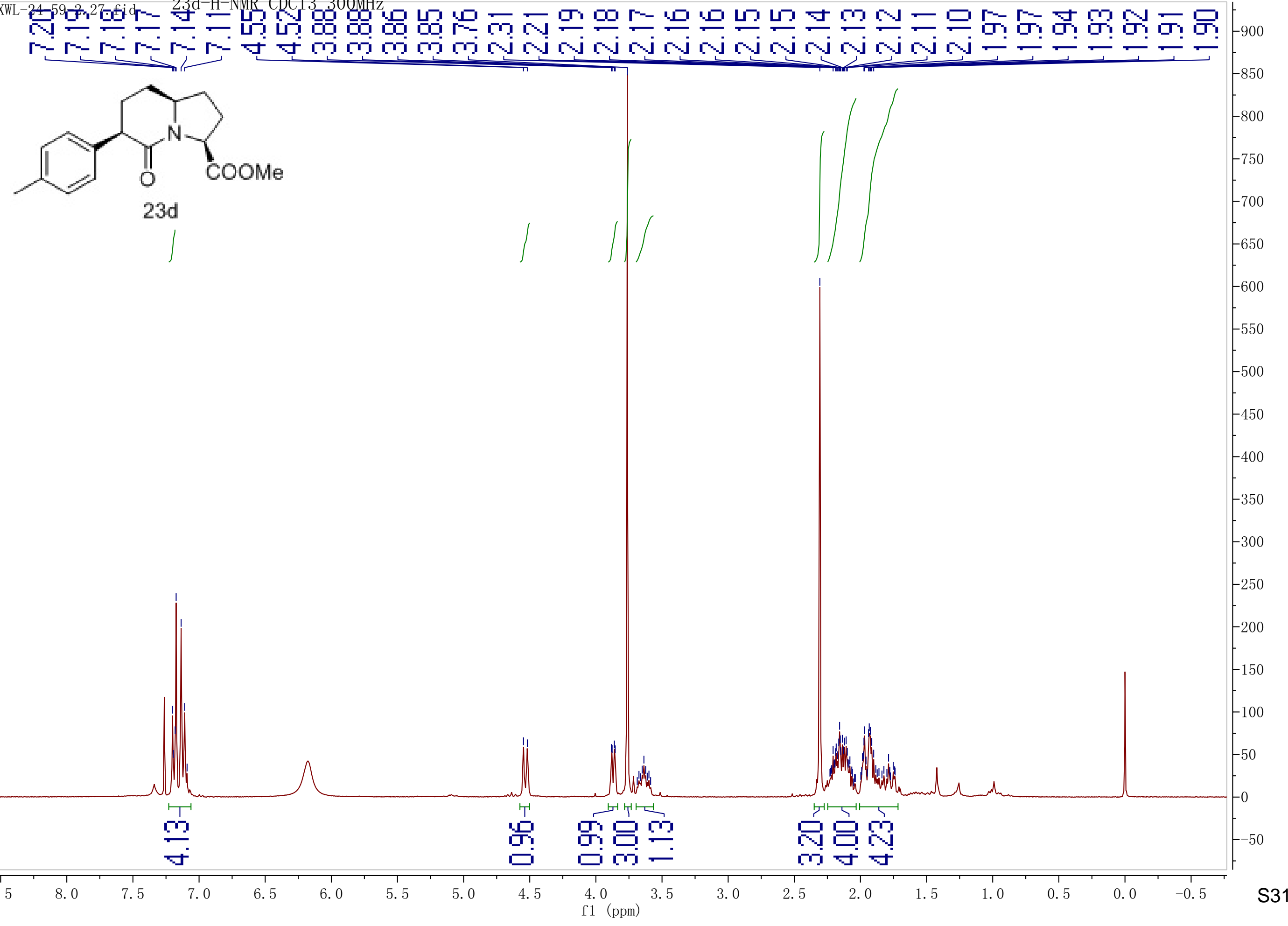


XWL-24-59-2-1. 3Afitit 23d-C-NMR CDC13

$0 \mathrm{j}$

i--

口ם

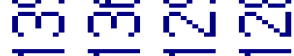

$-5 \div 5$

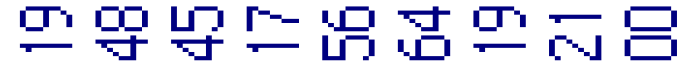
뭄ำ
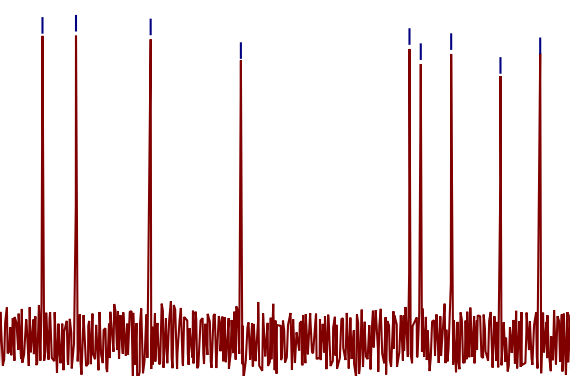
XWL-24+68-10.

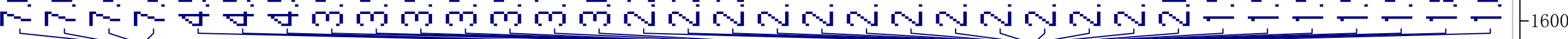
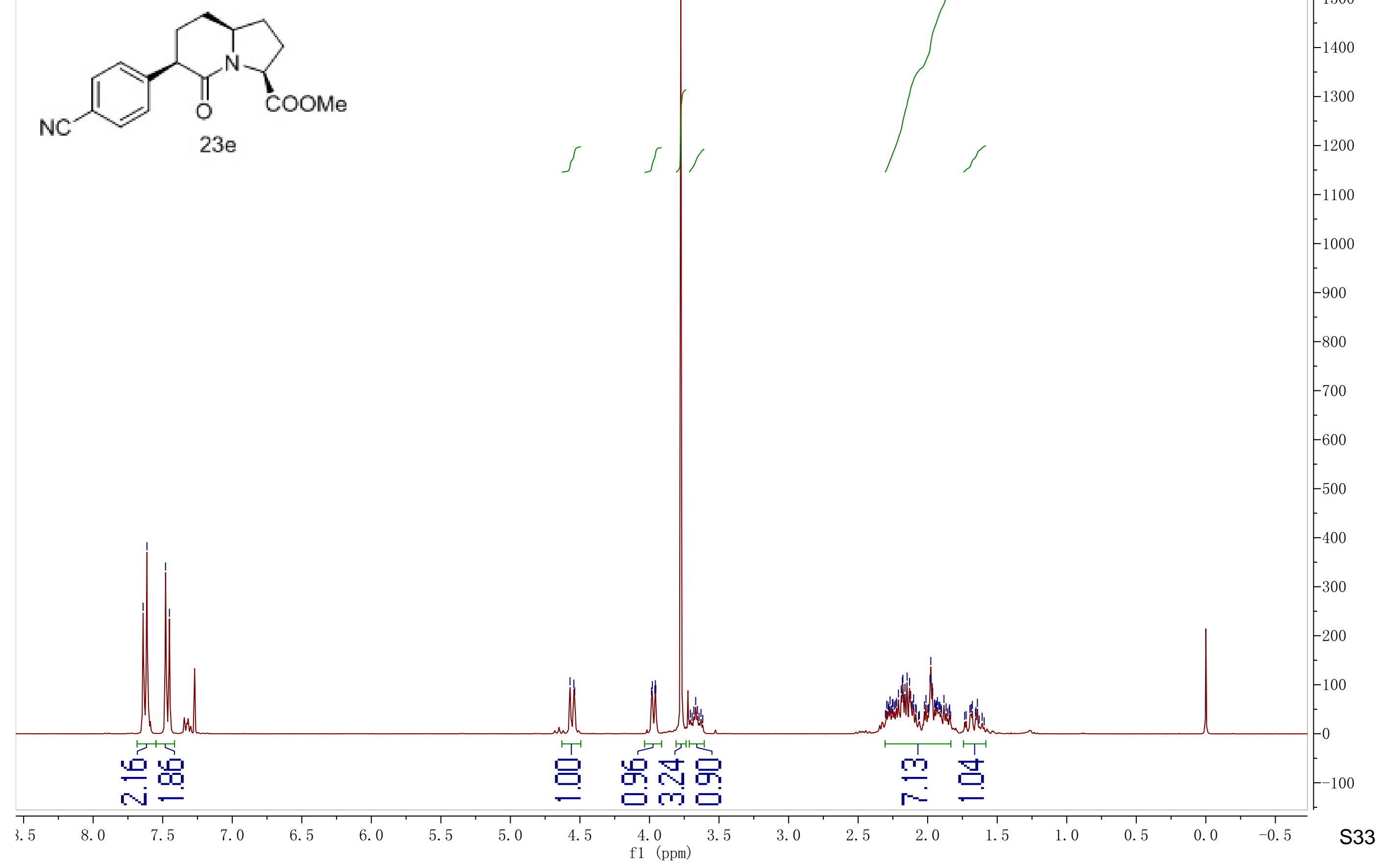
XWL-24-68-10C. 15. fid

XWL-24-68-10C CDCI3 300M

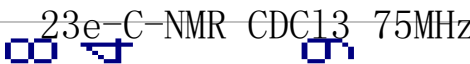

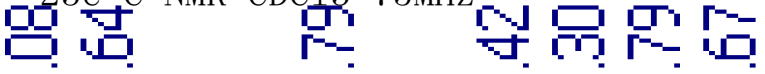

I-

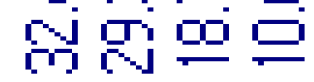
in$\frac{1}{1} \div$

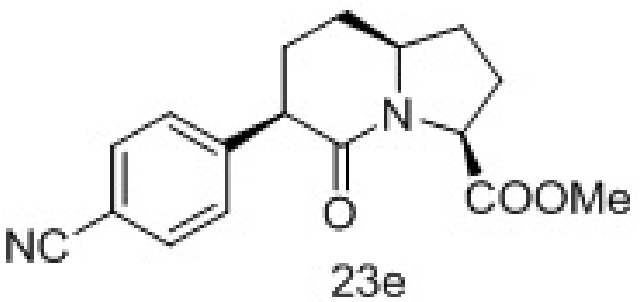

$23 e$

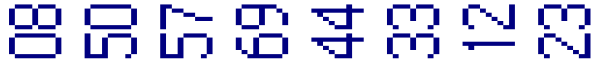

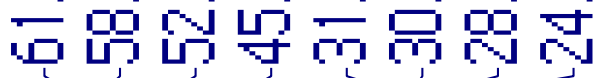




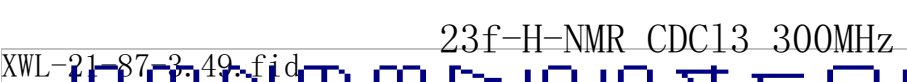

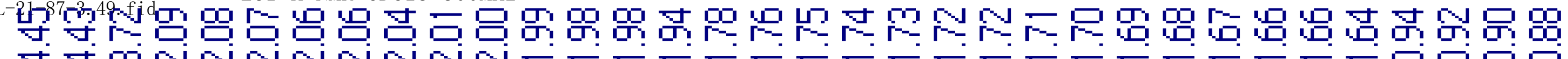
ه

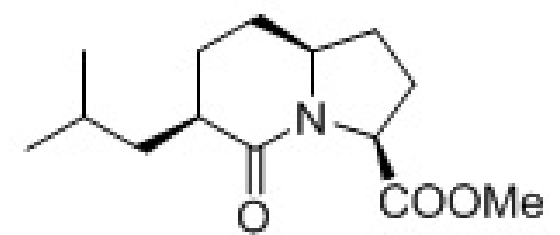

$23 f$
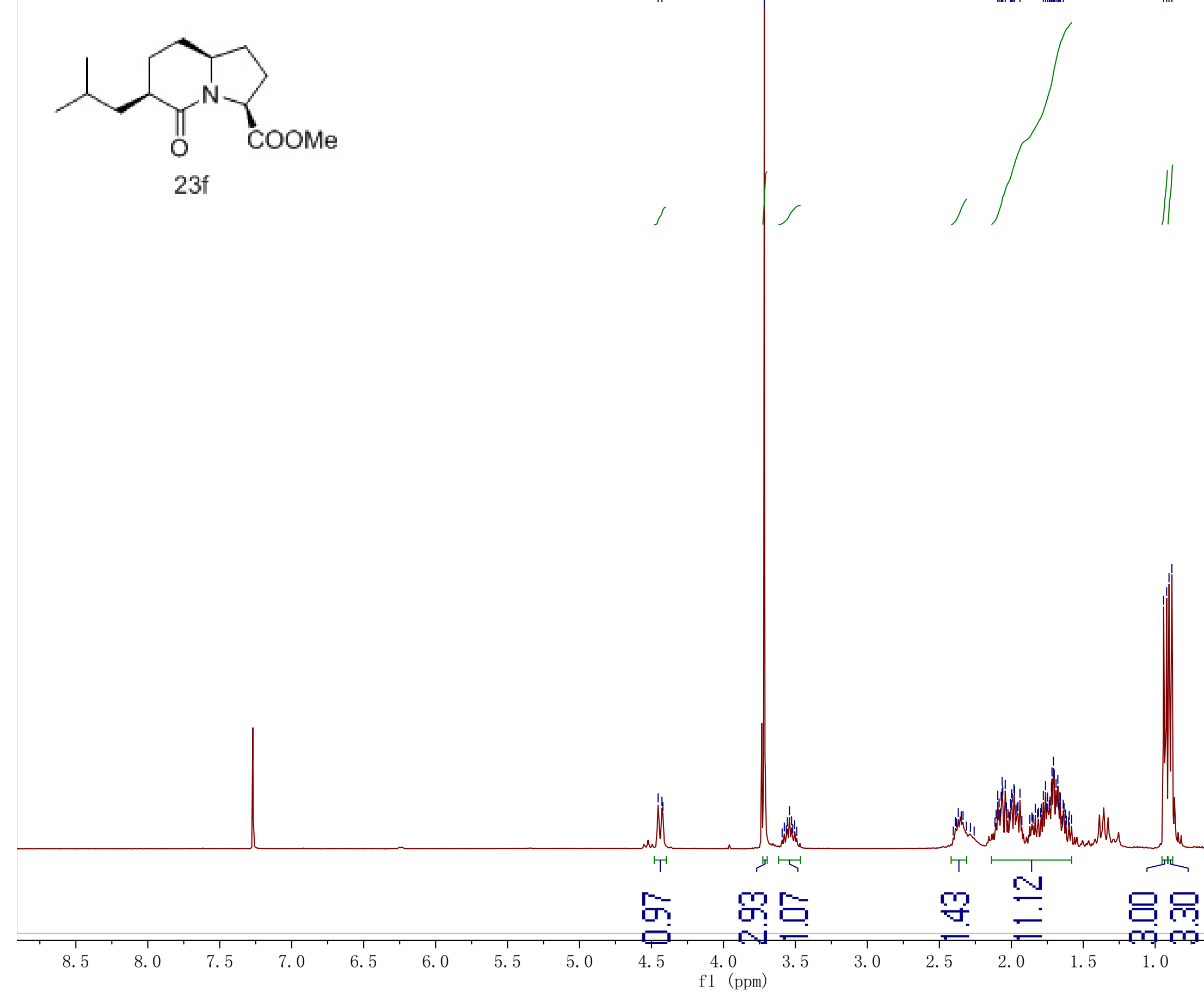


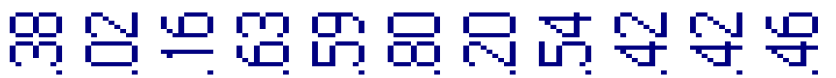

$0 \mathrm{j}$

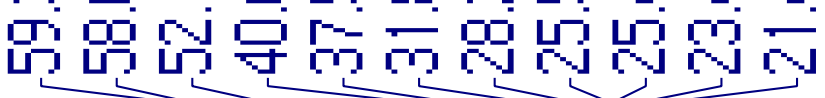

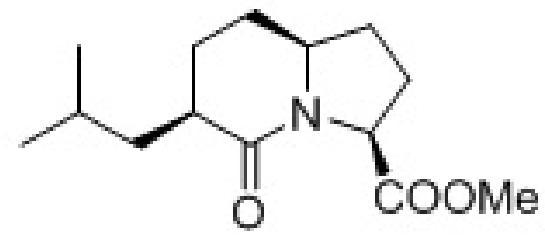

$23 f$ 


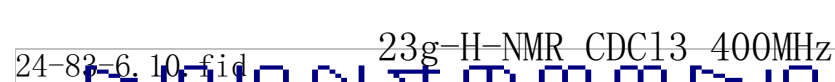
寸 田
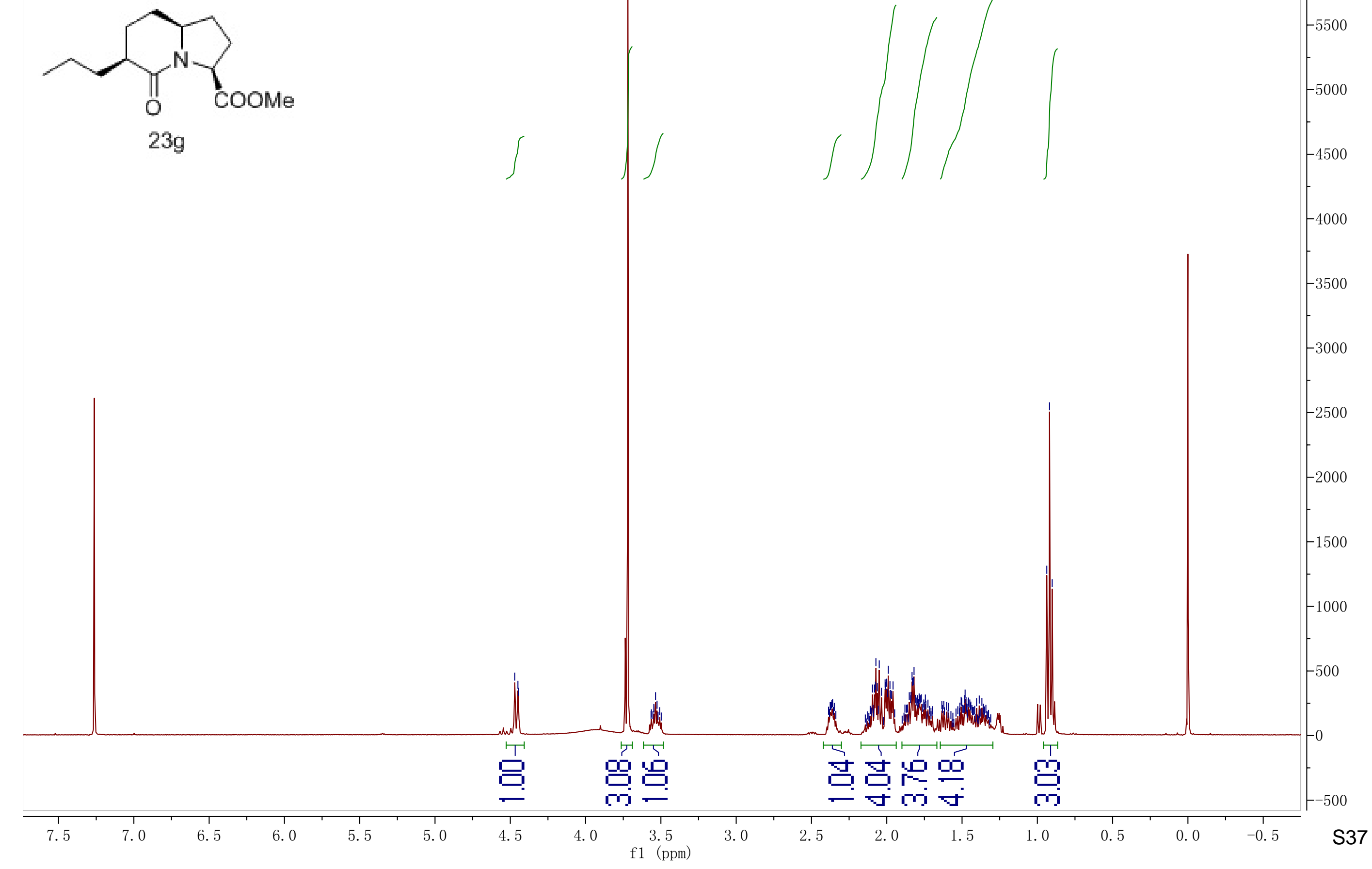


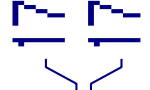

年-

पi

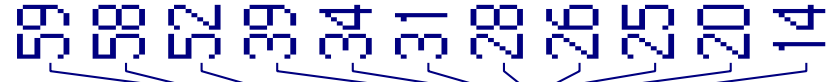

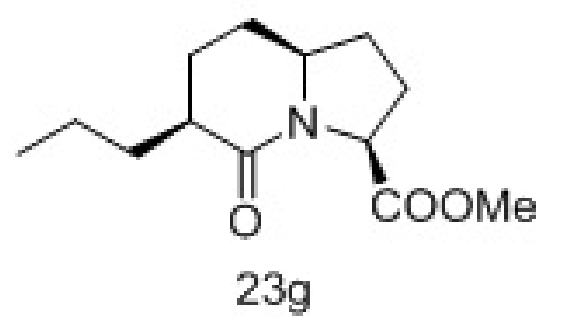


Xw-220 ar a
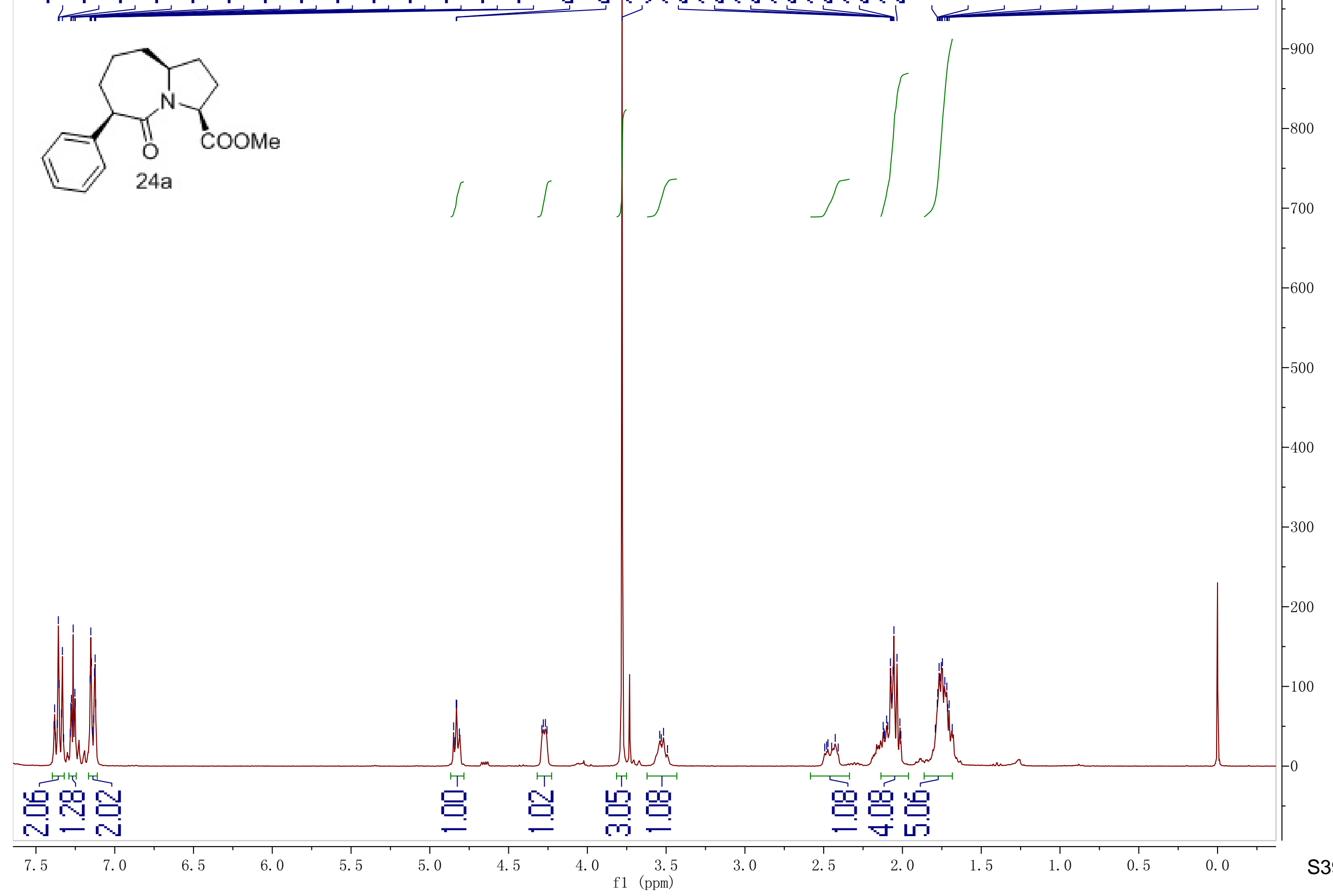
XWL-22-10-4-C. 32. fid 24 -C-XMR CDC13 75MHz
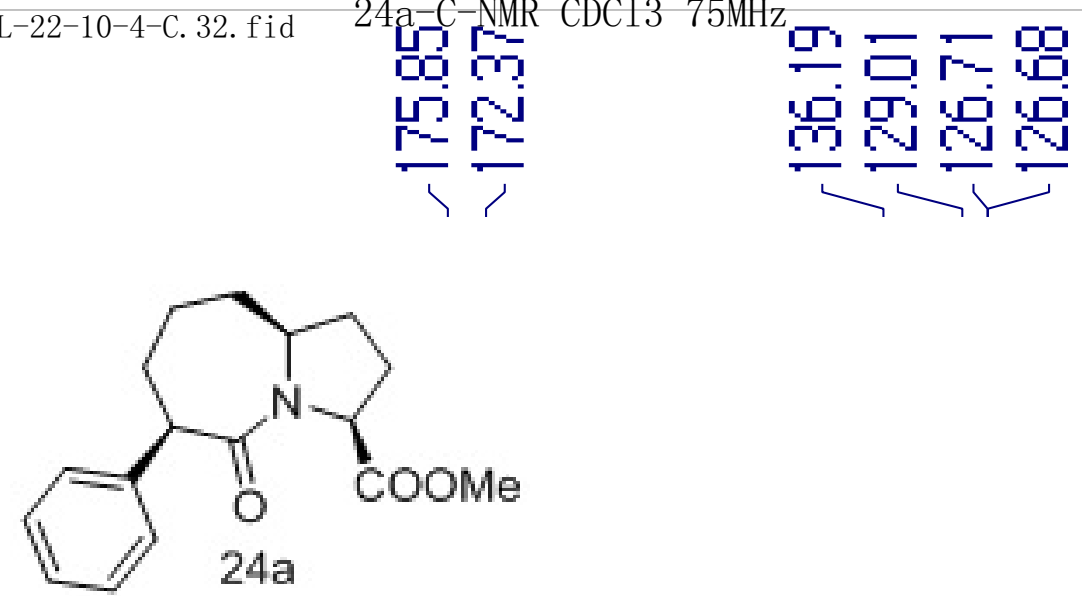

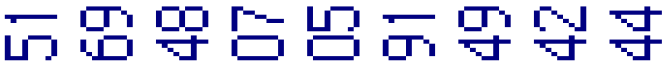
- 


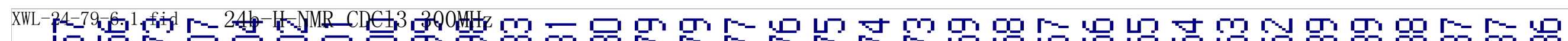
4

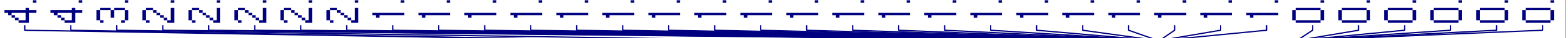
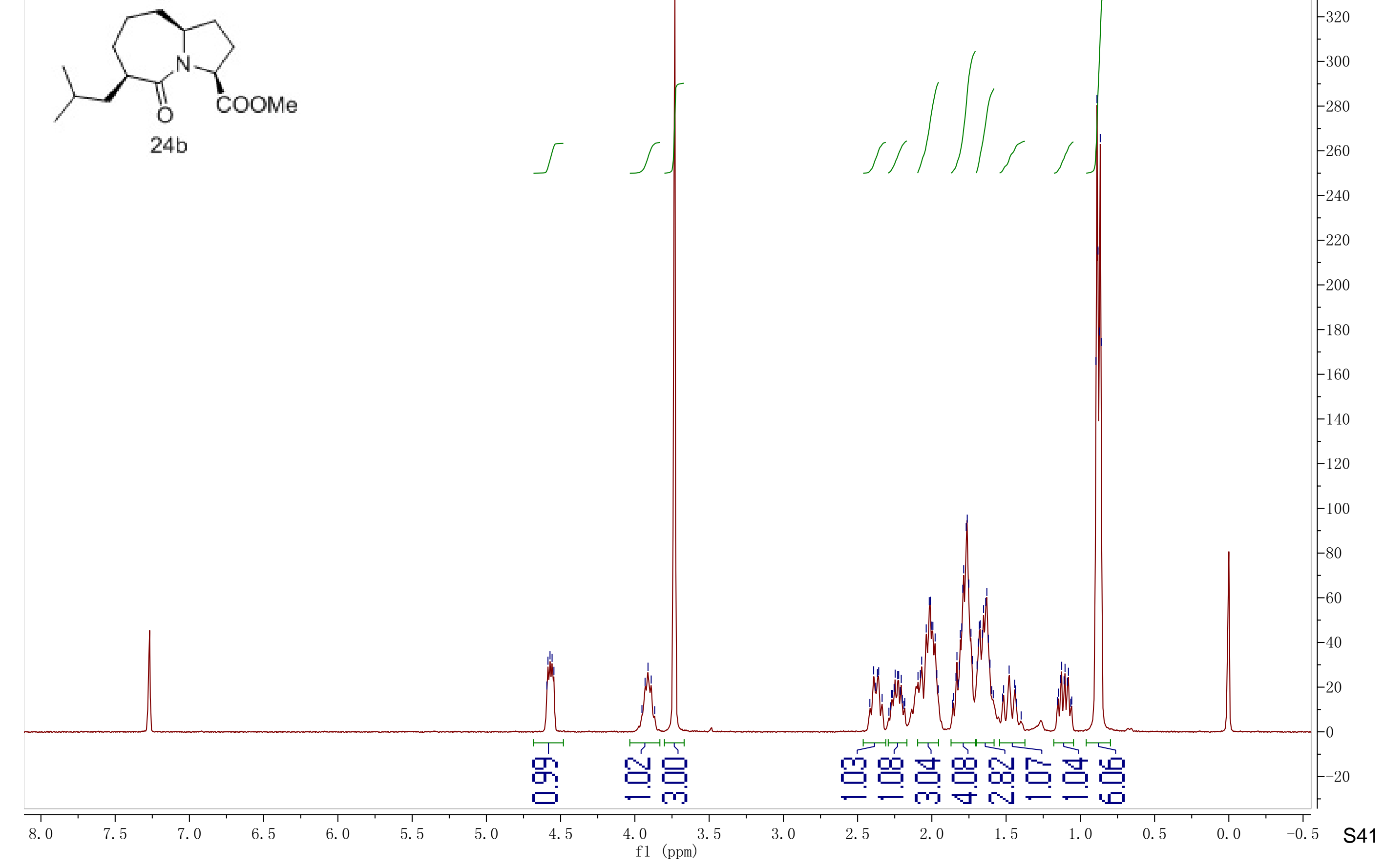
$\frac{1}{2}$

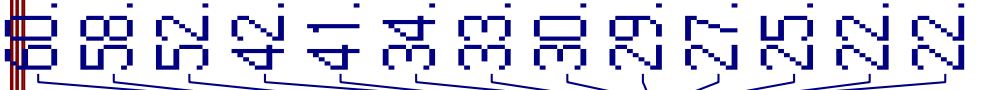
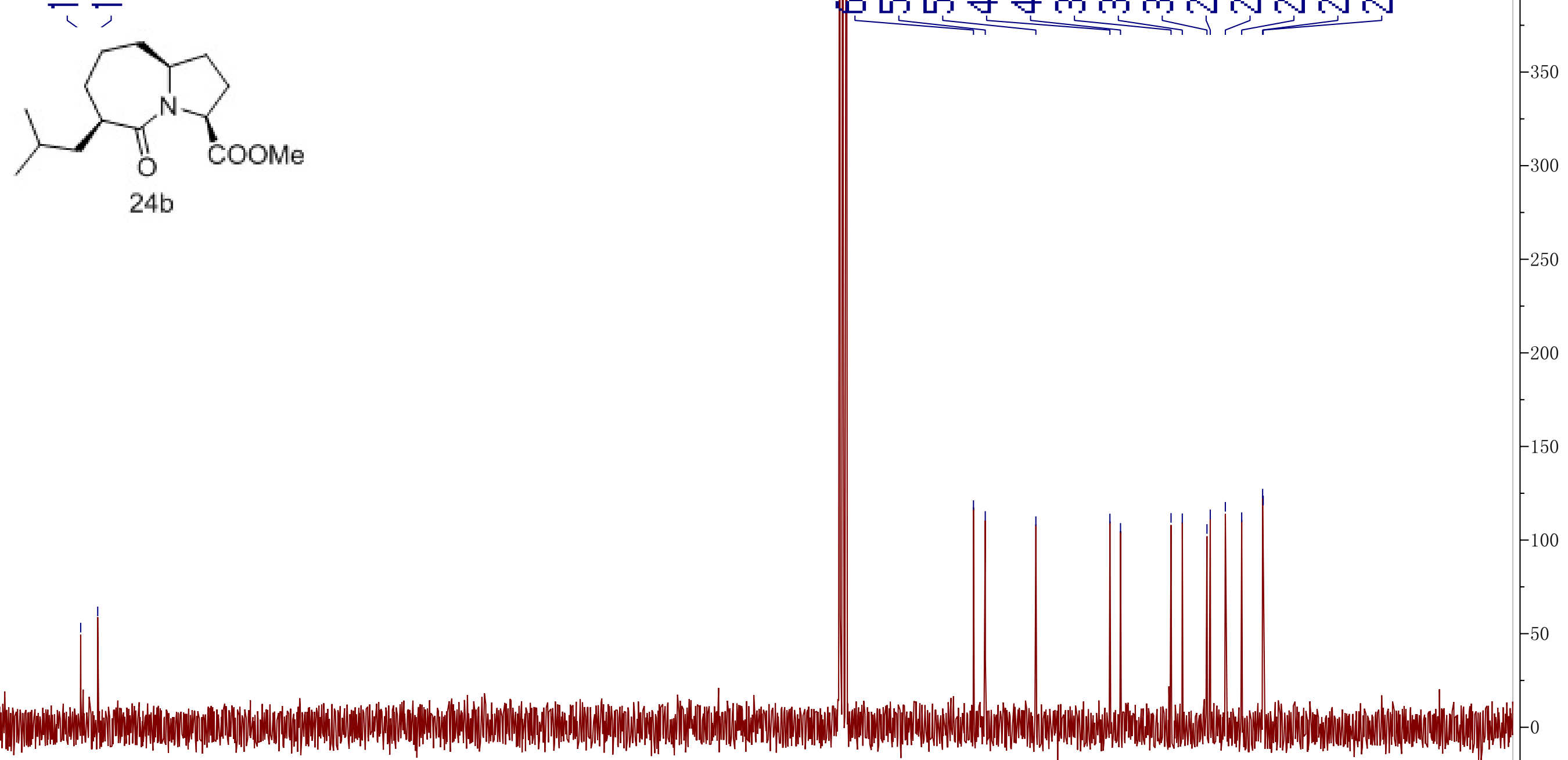

N

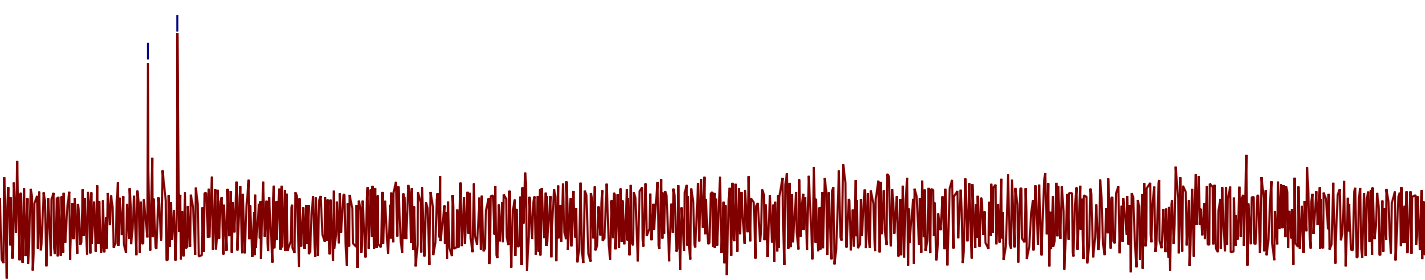


9

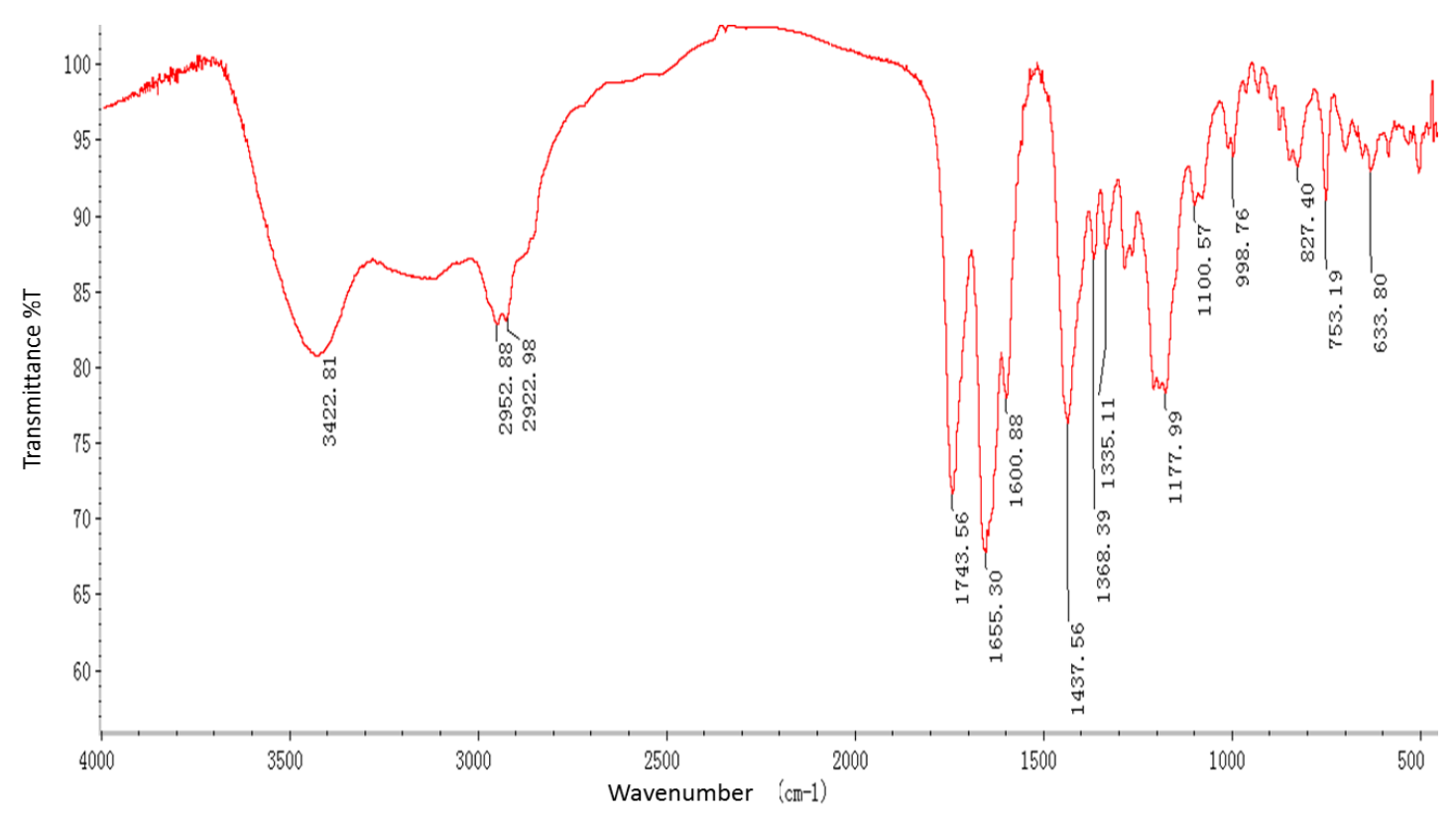

10

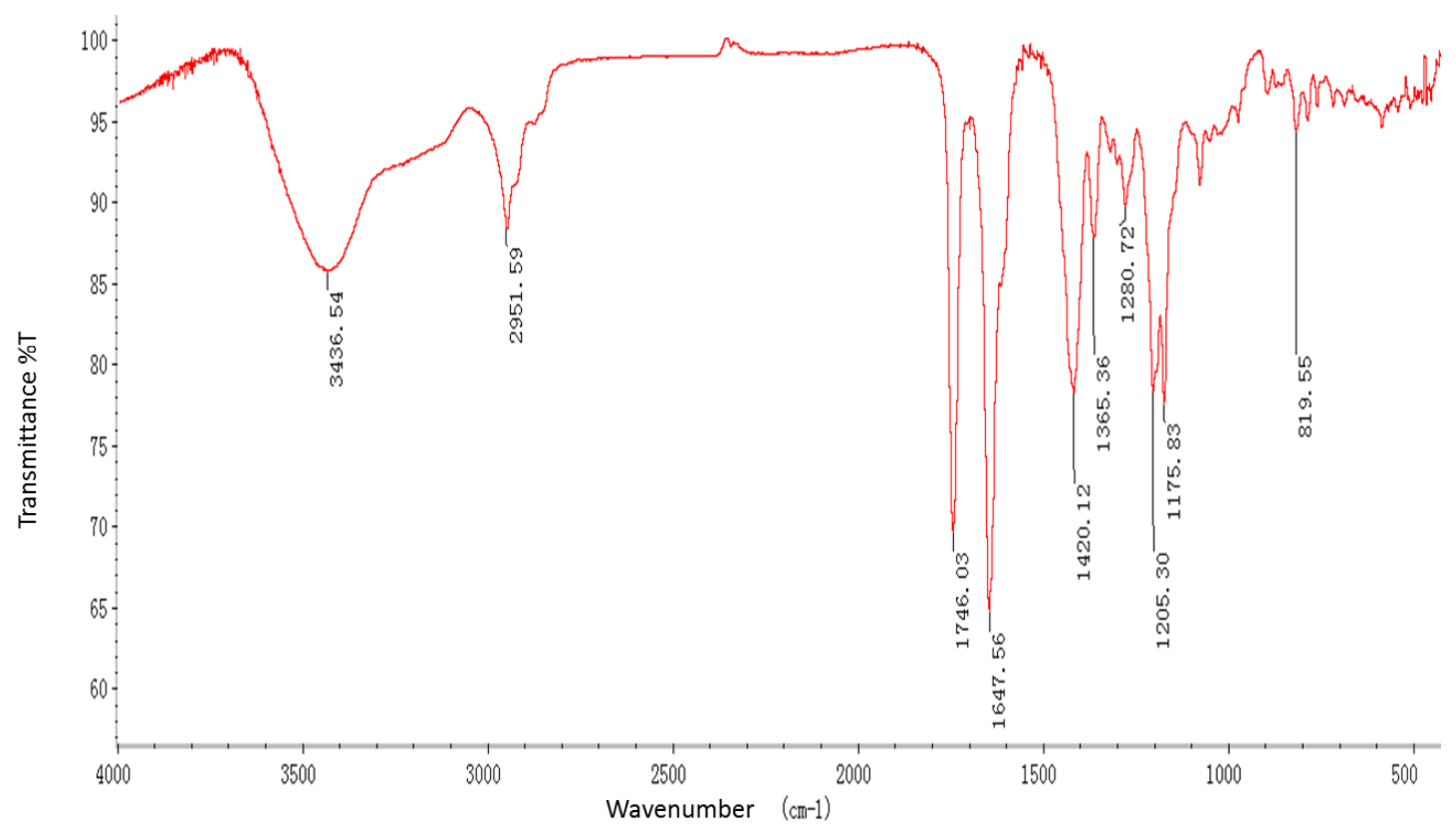

S43 


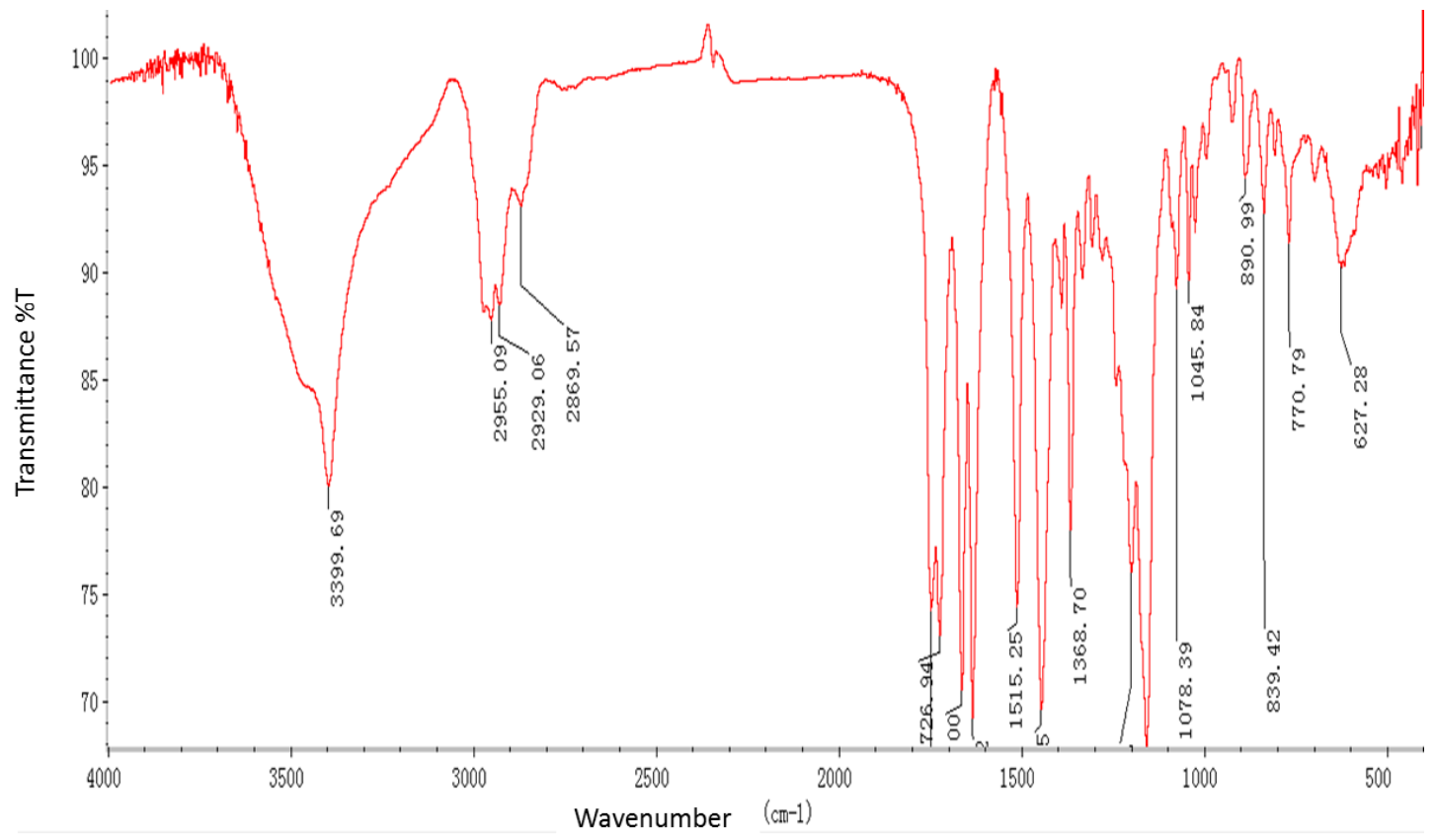

5

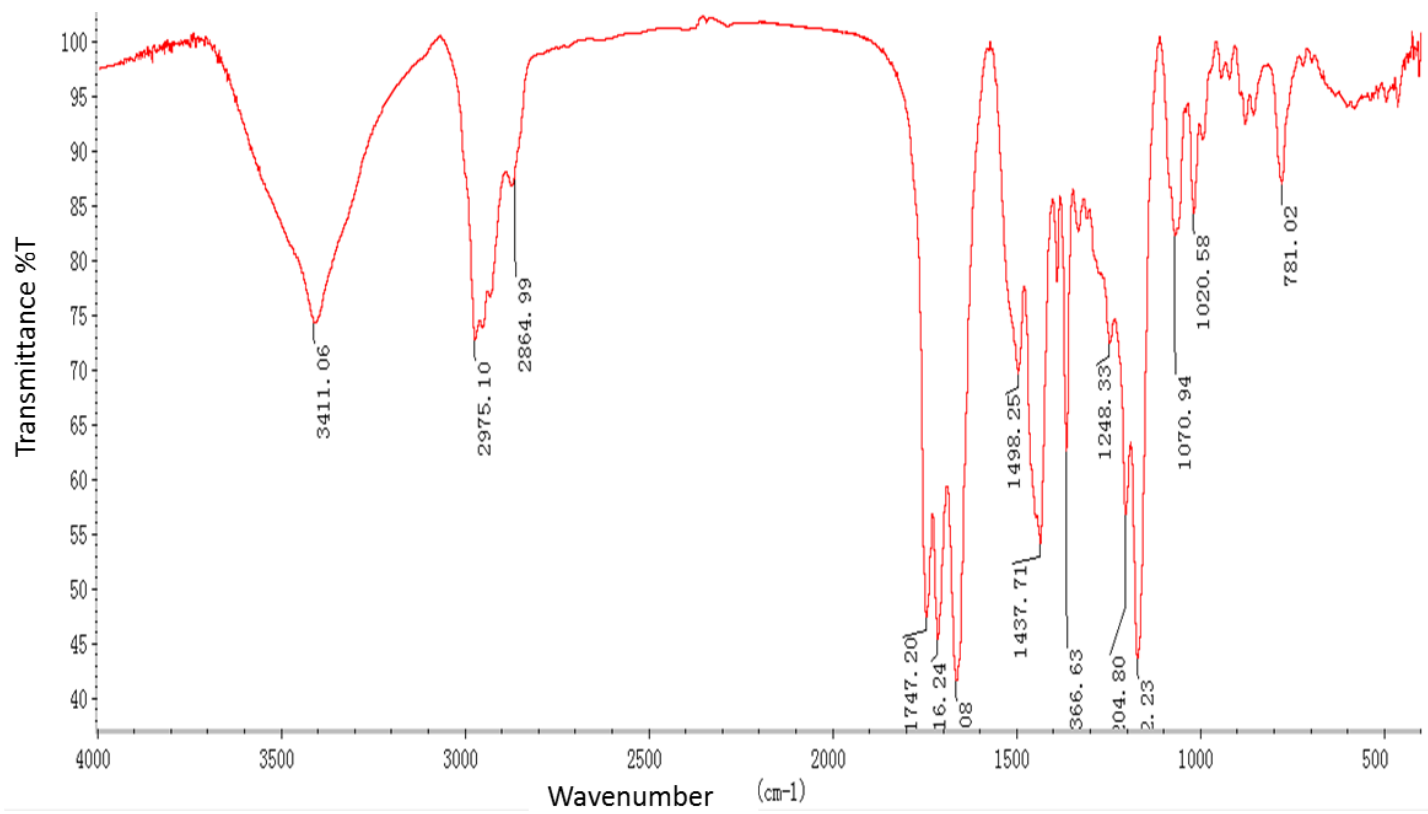




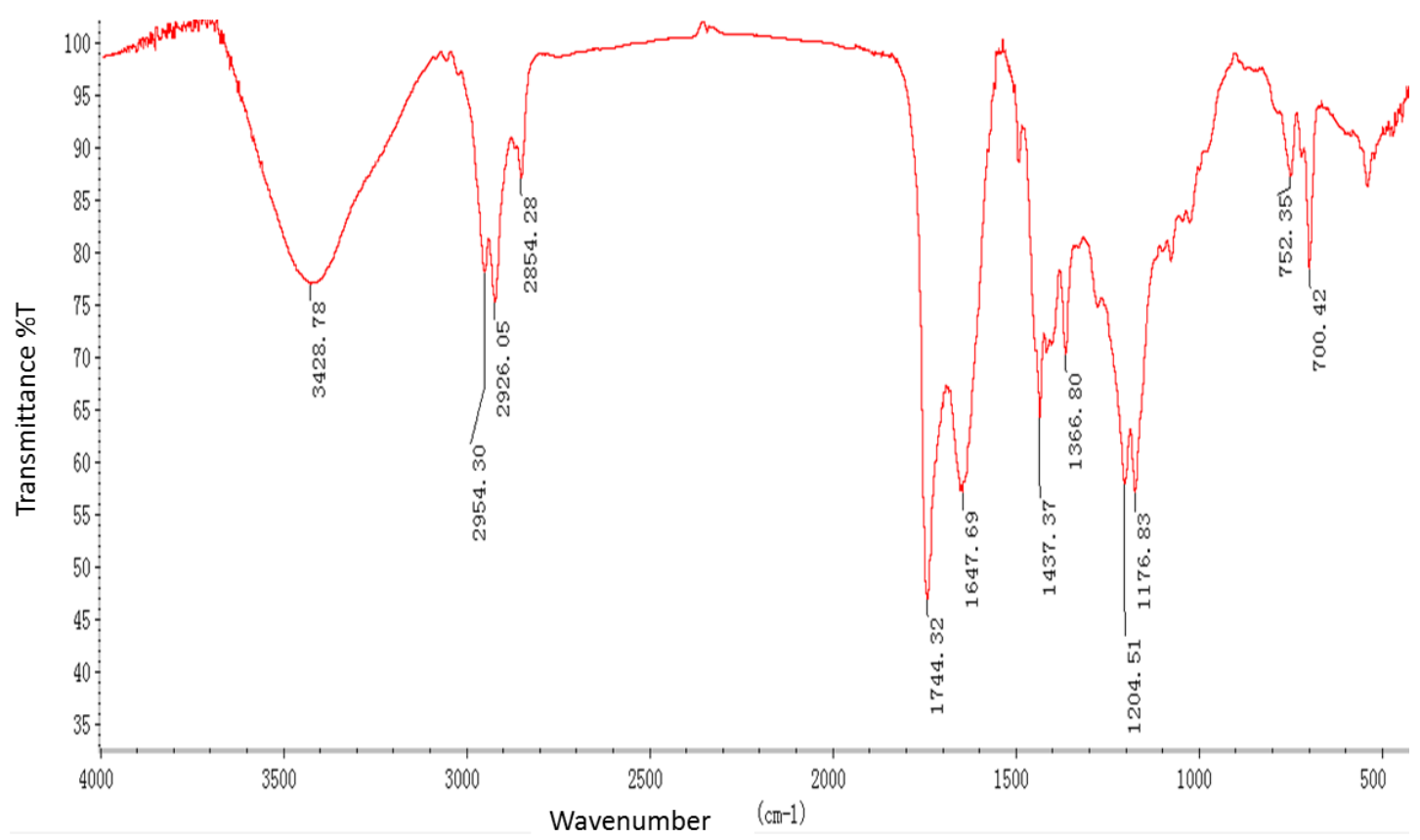

19

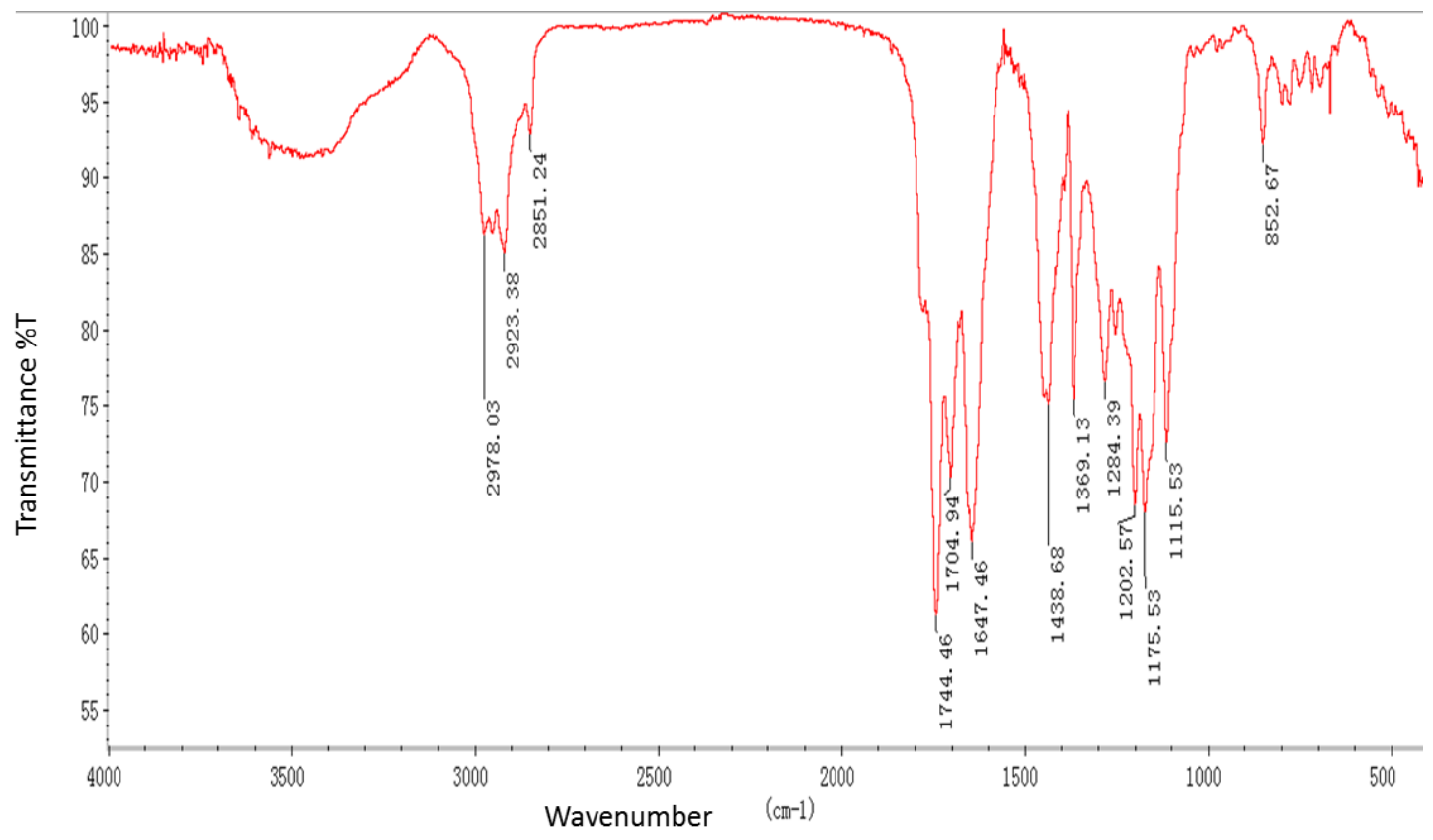




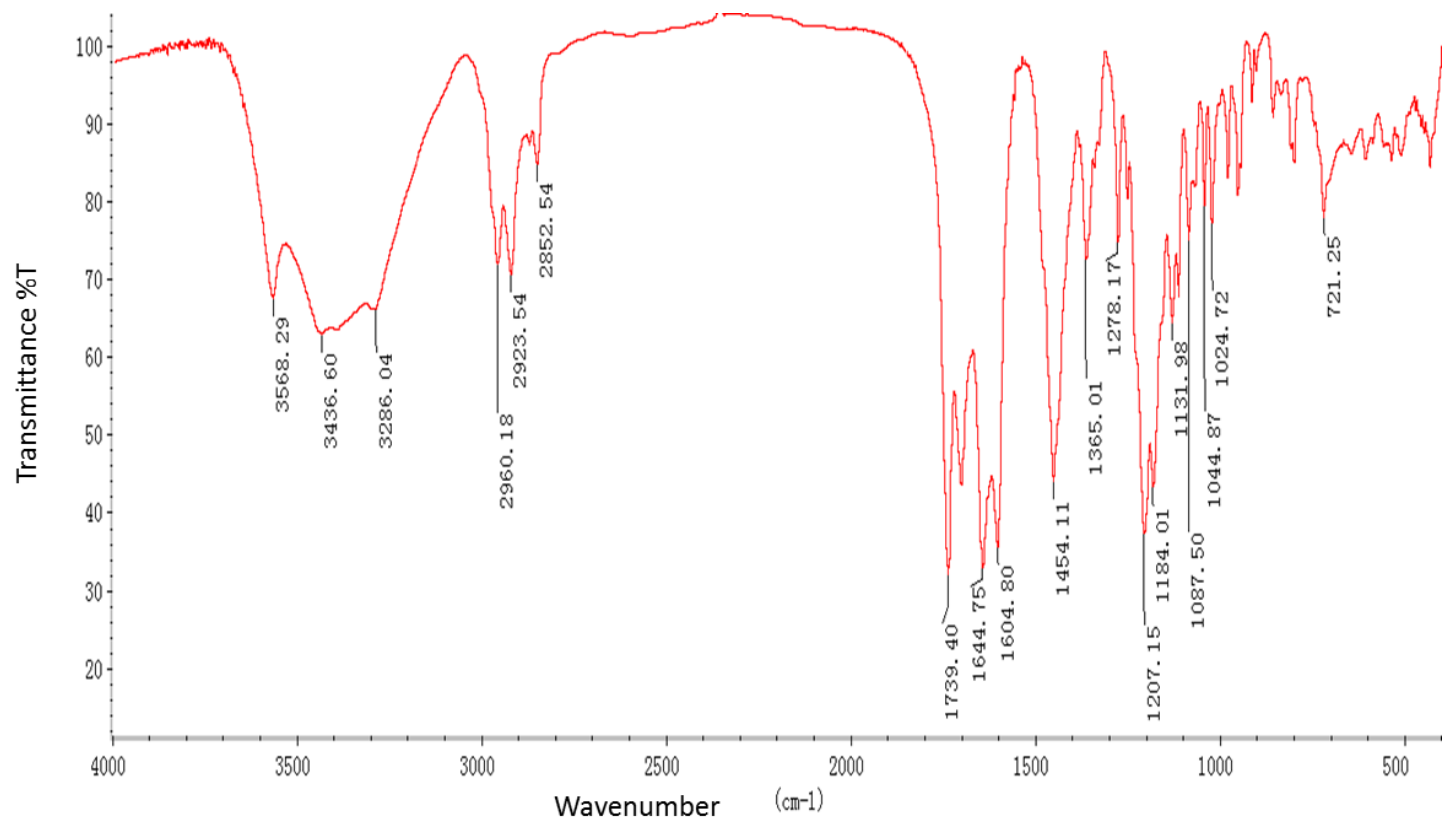

$22 a$

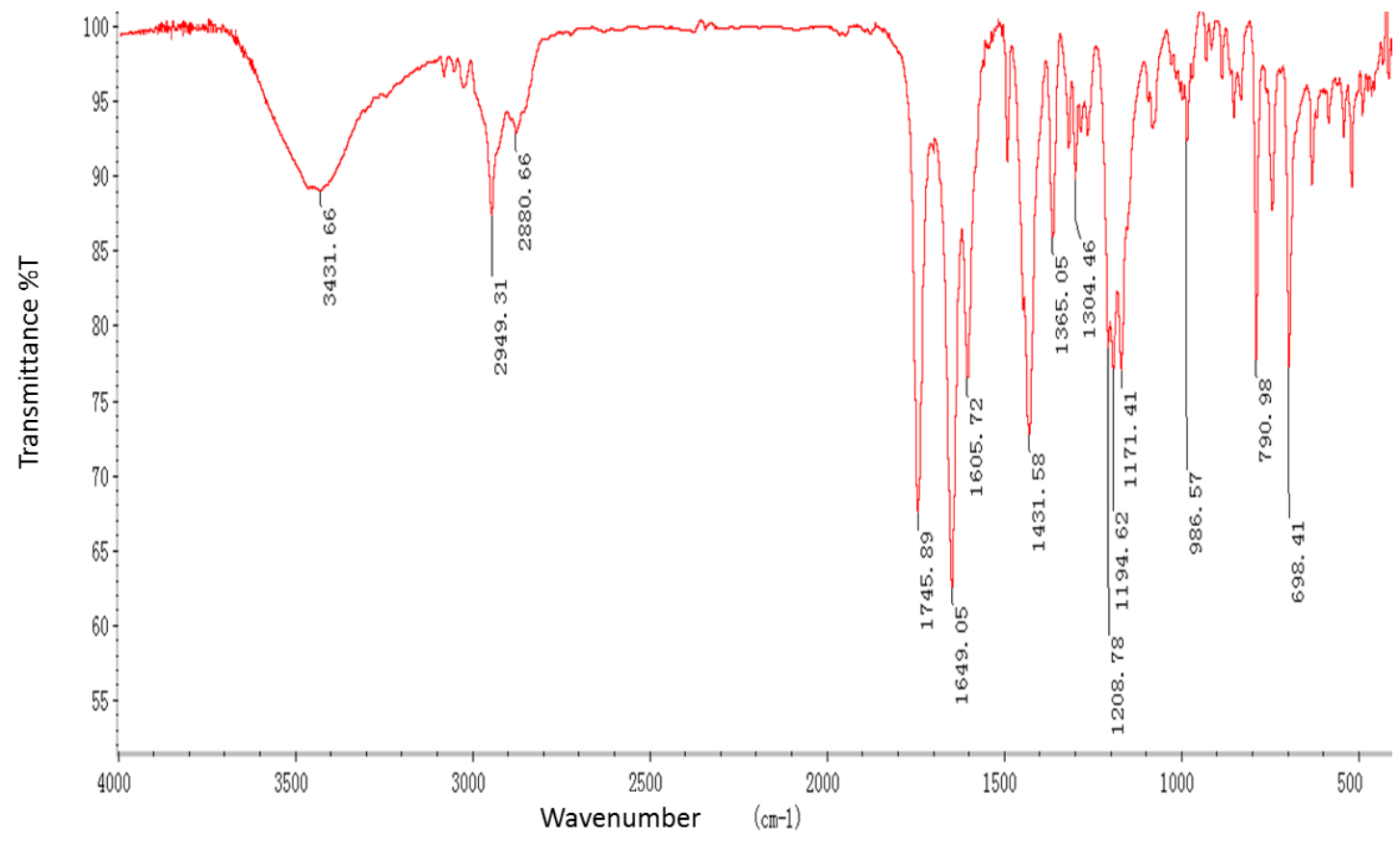




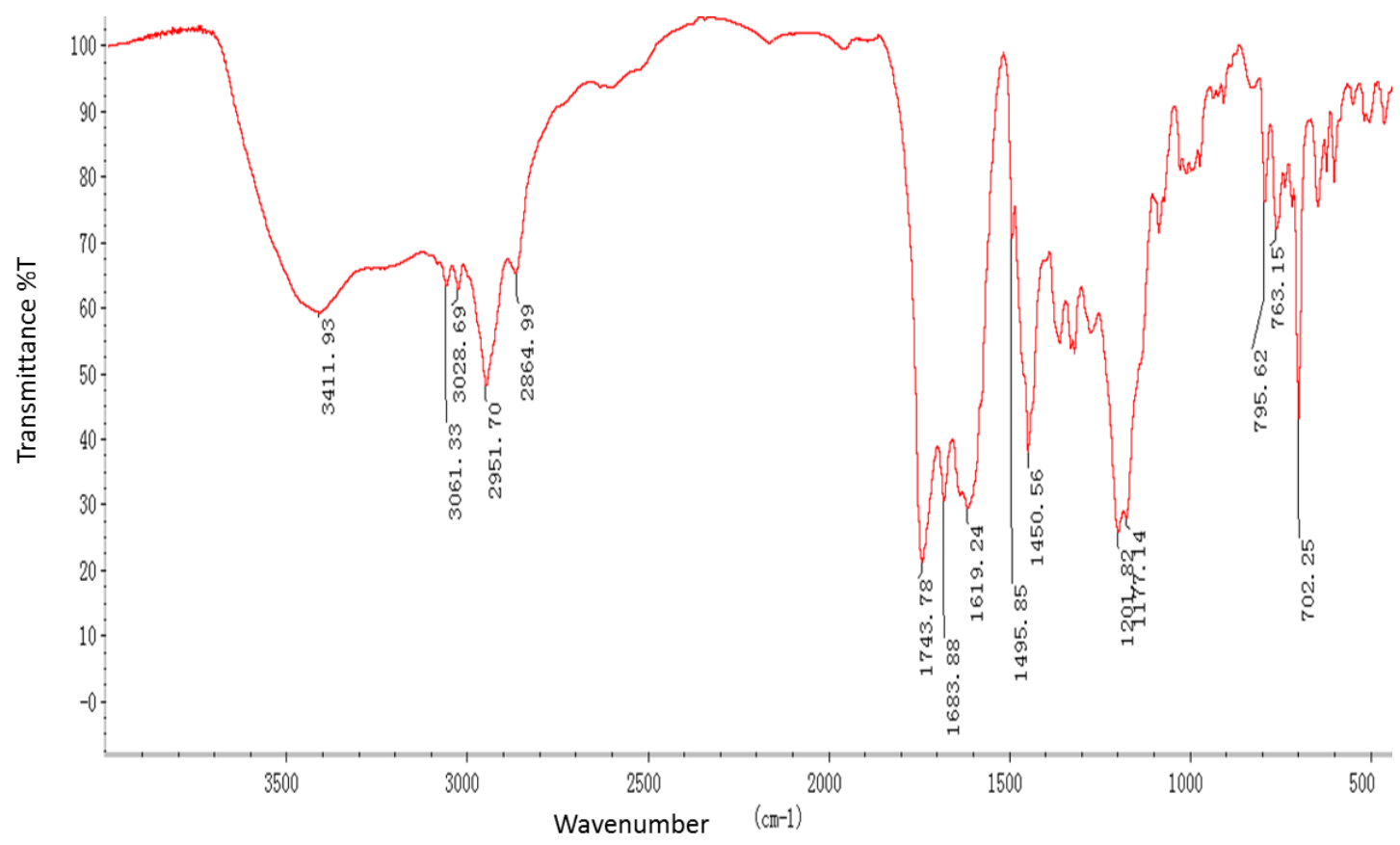

$23 b$

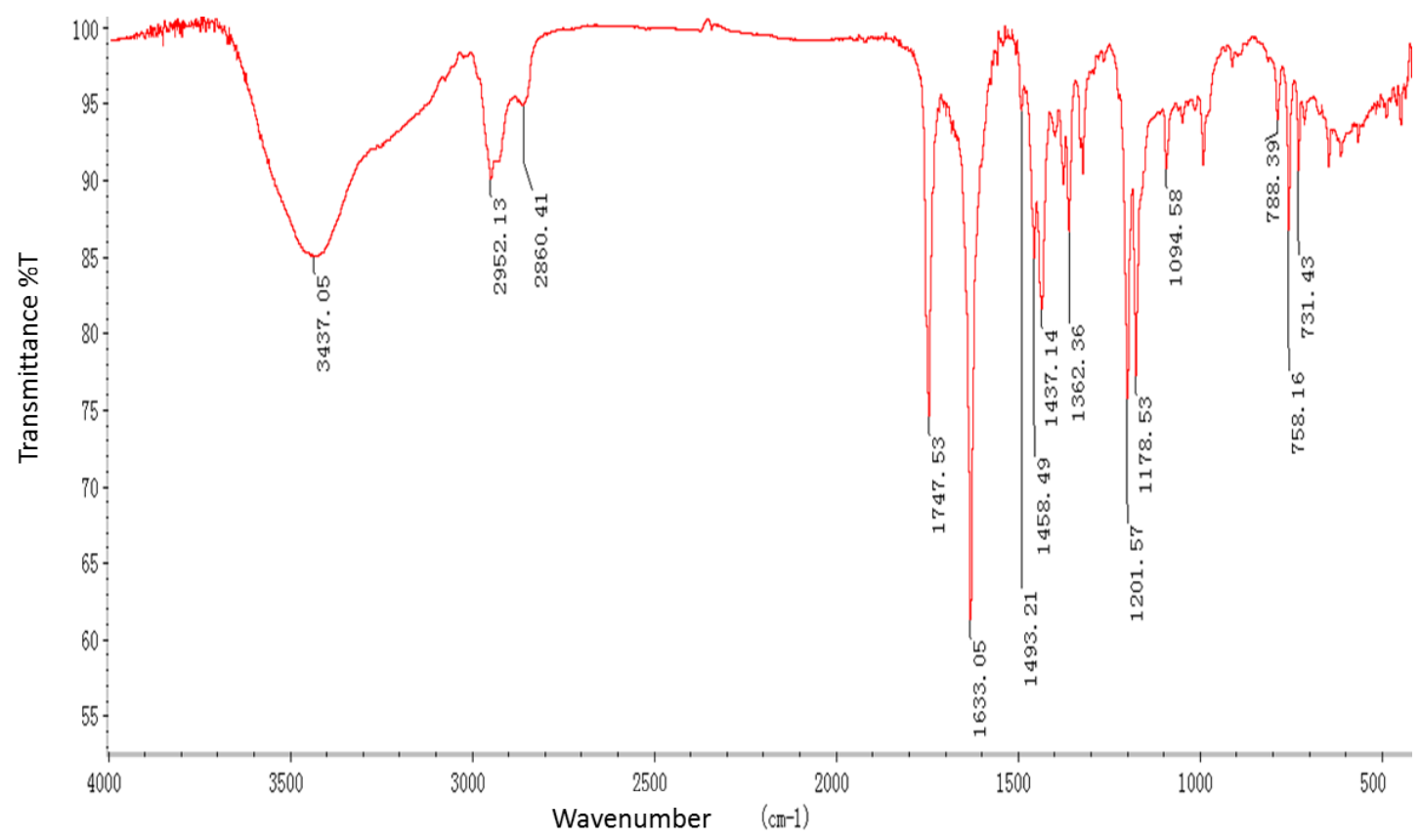




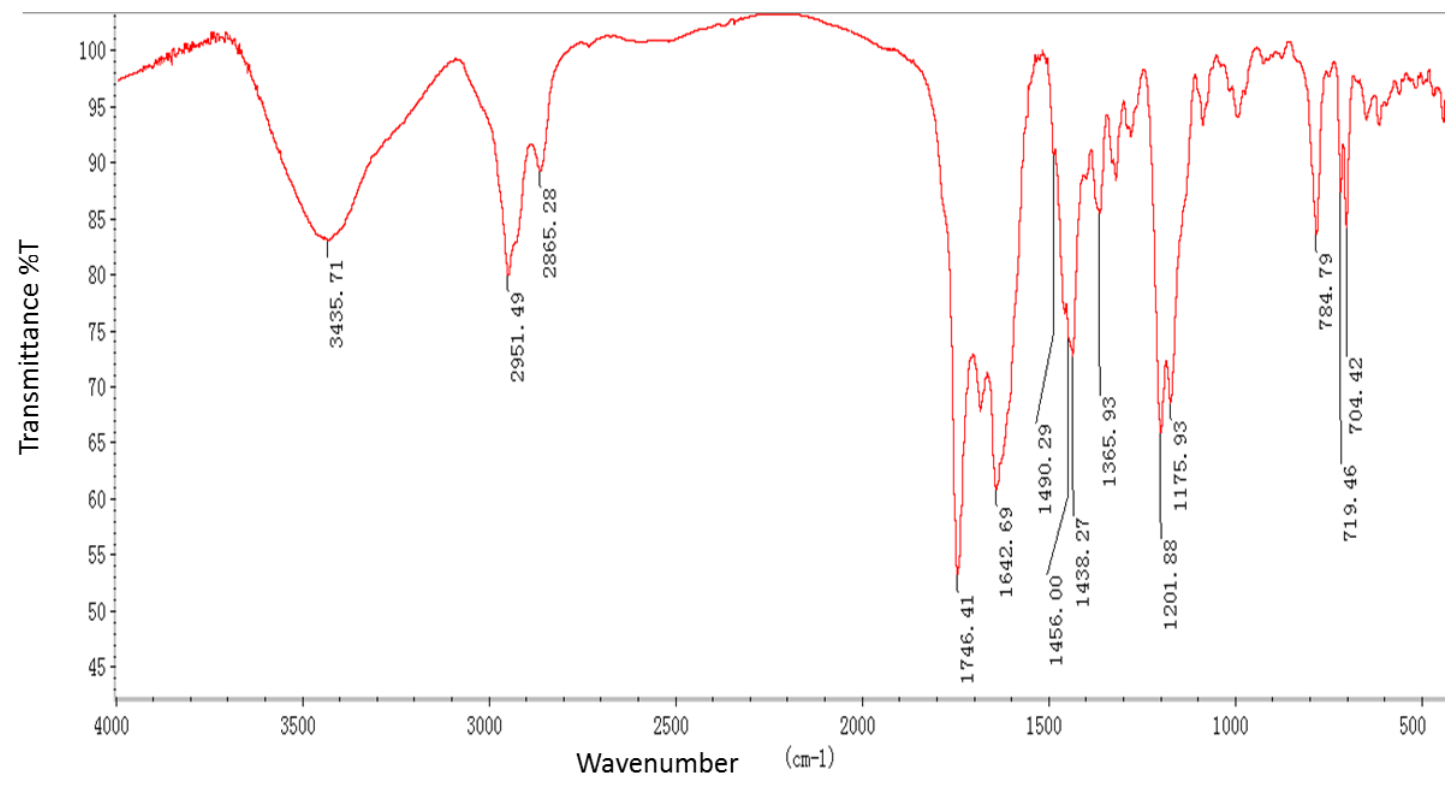

$23 d$

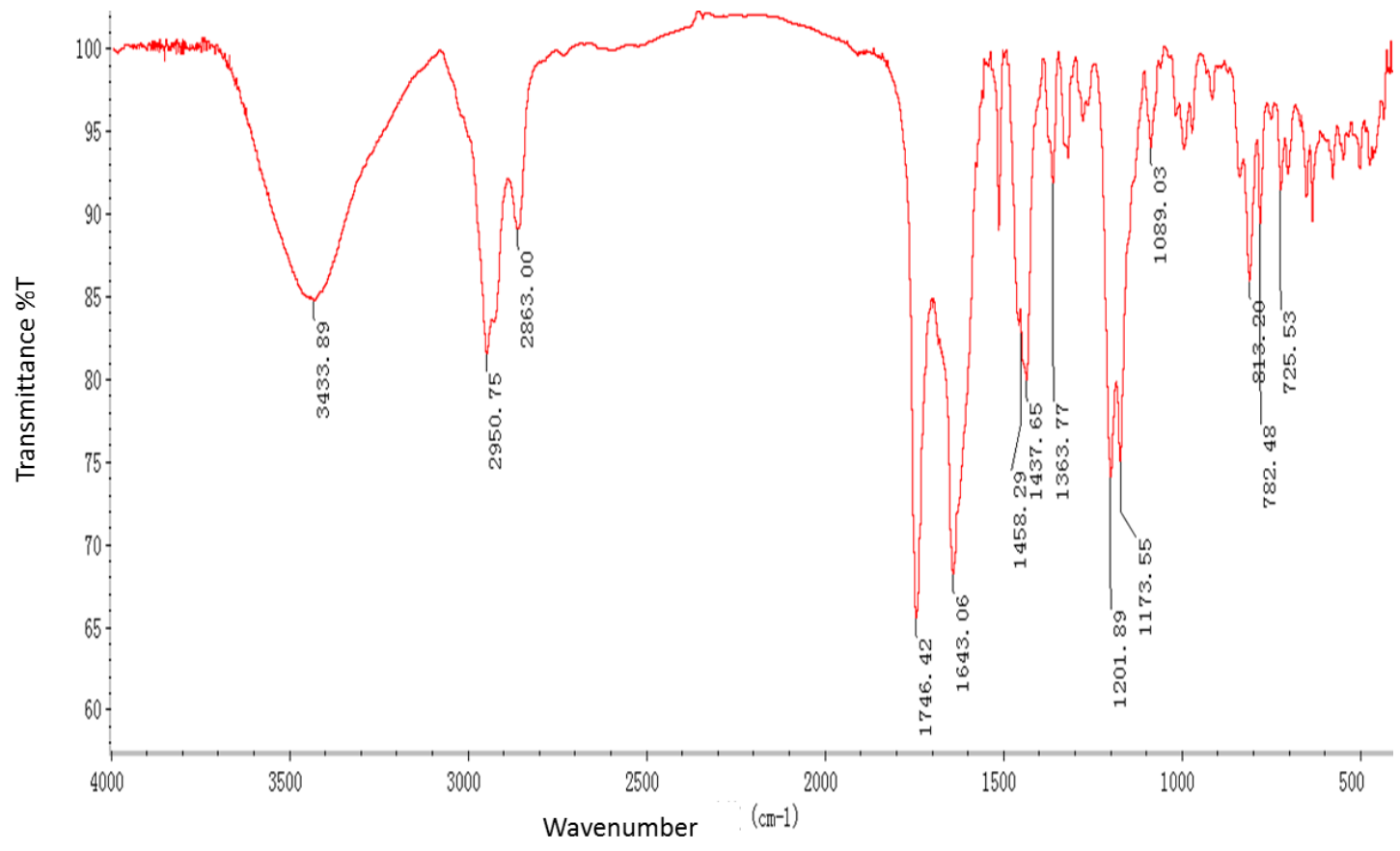




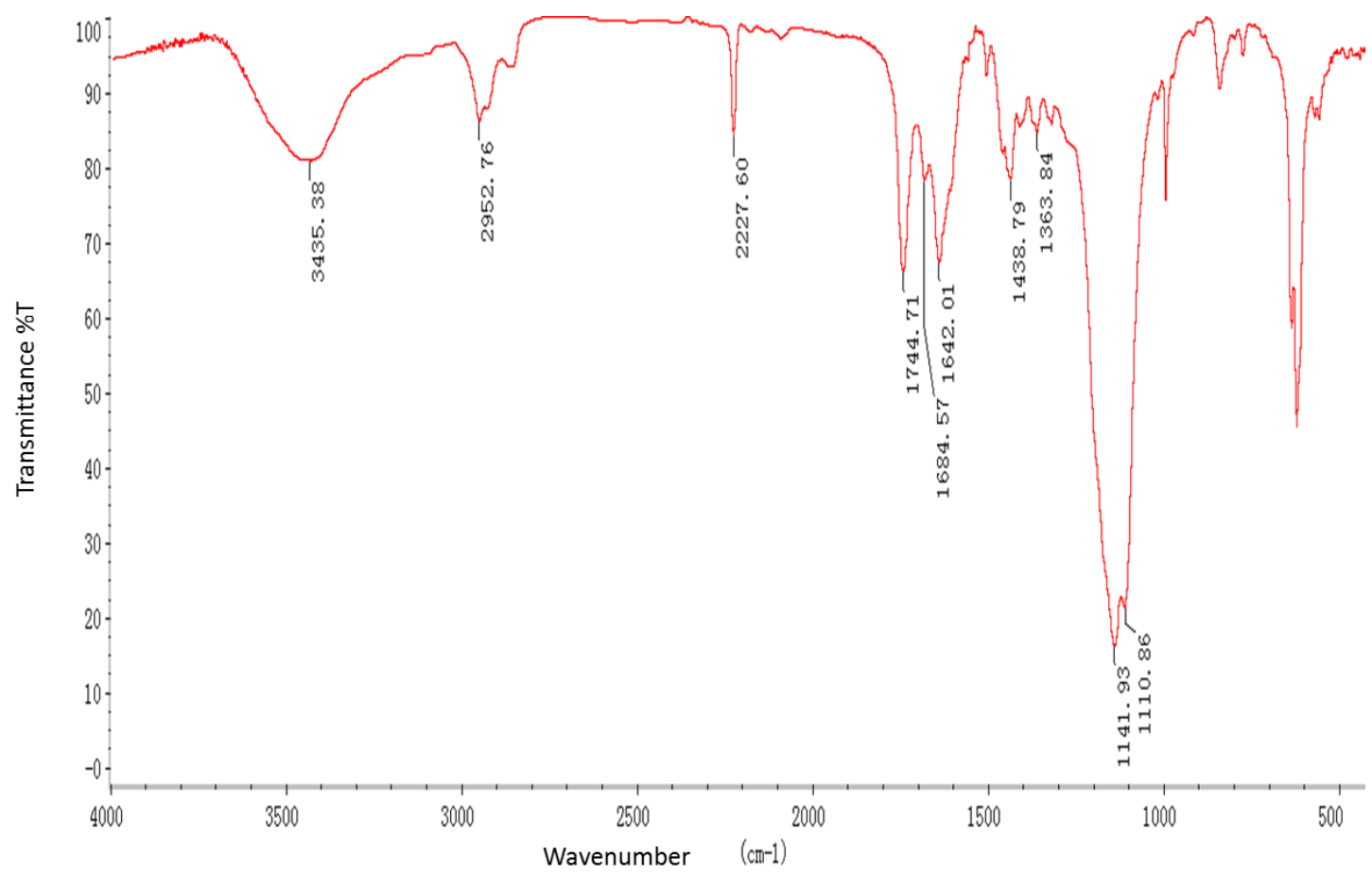

$23 f$

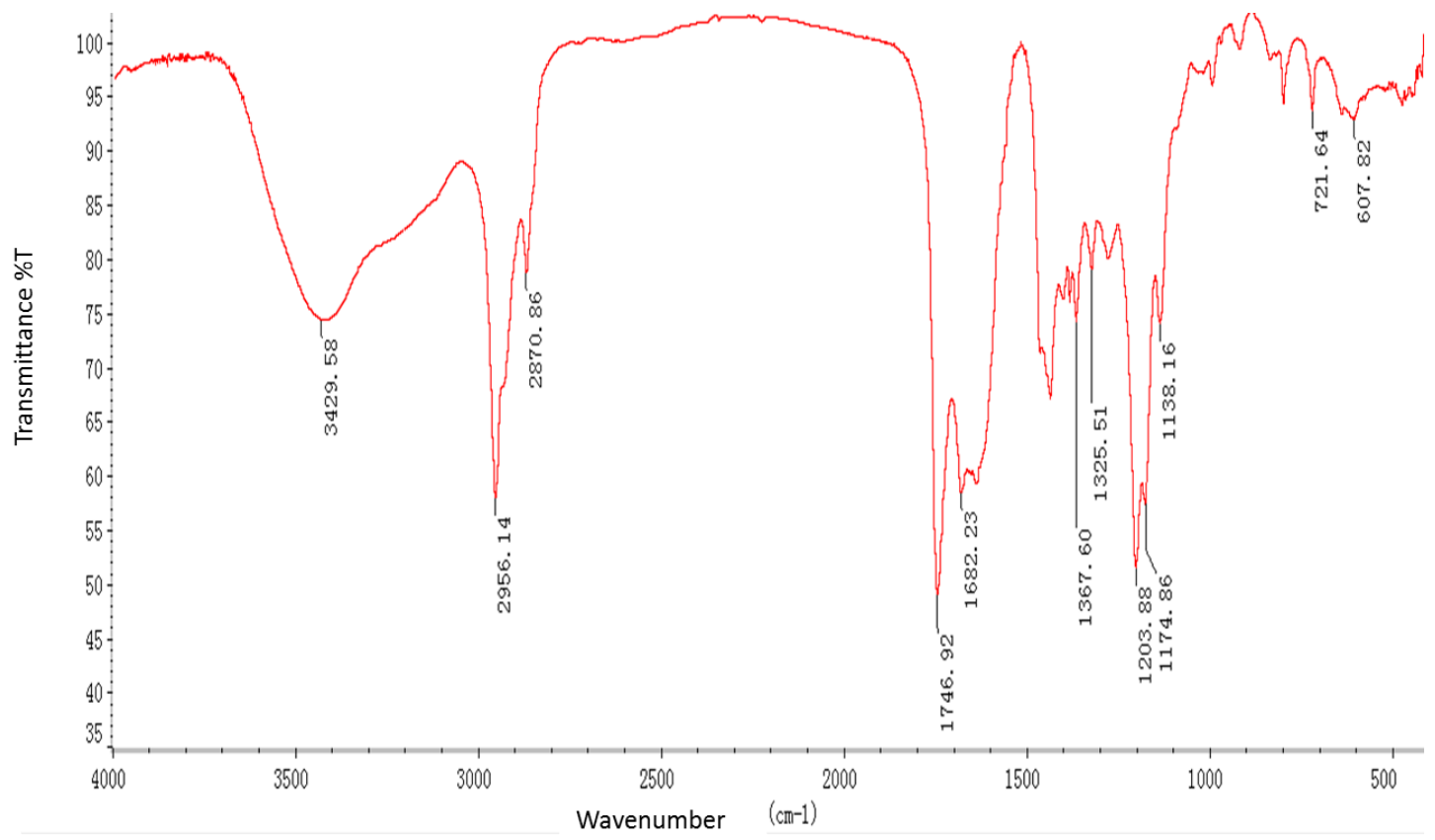




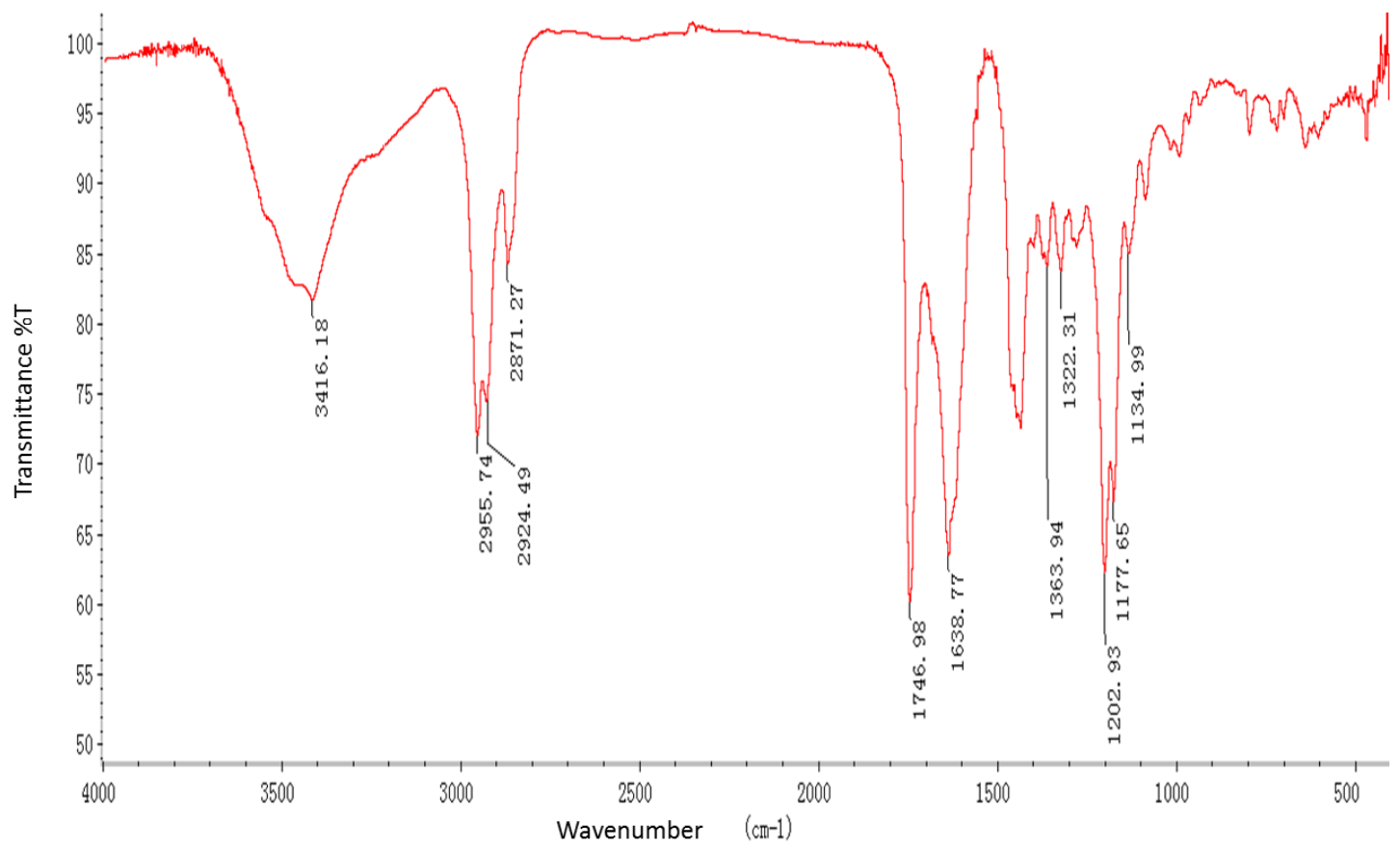

$24 a$

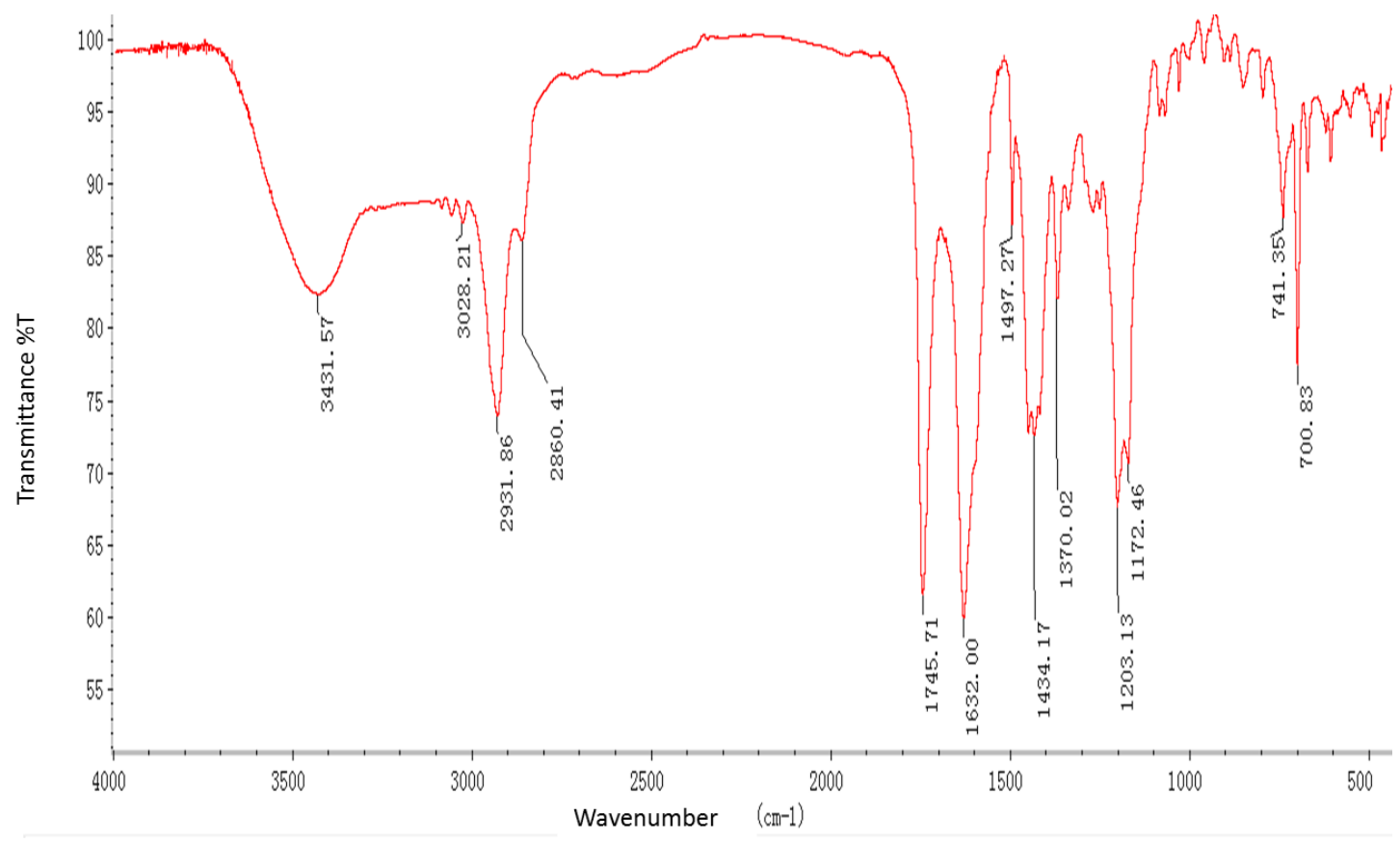




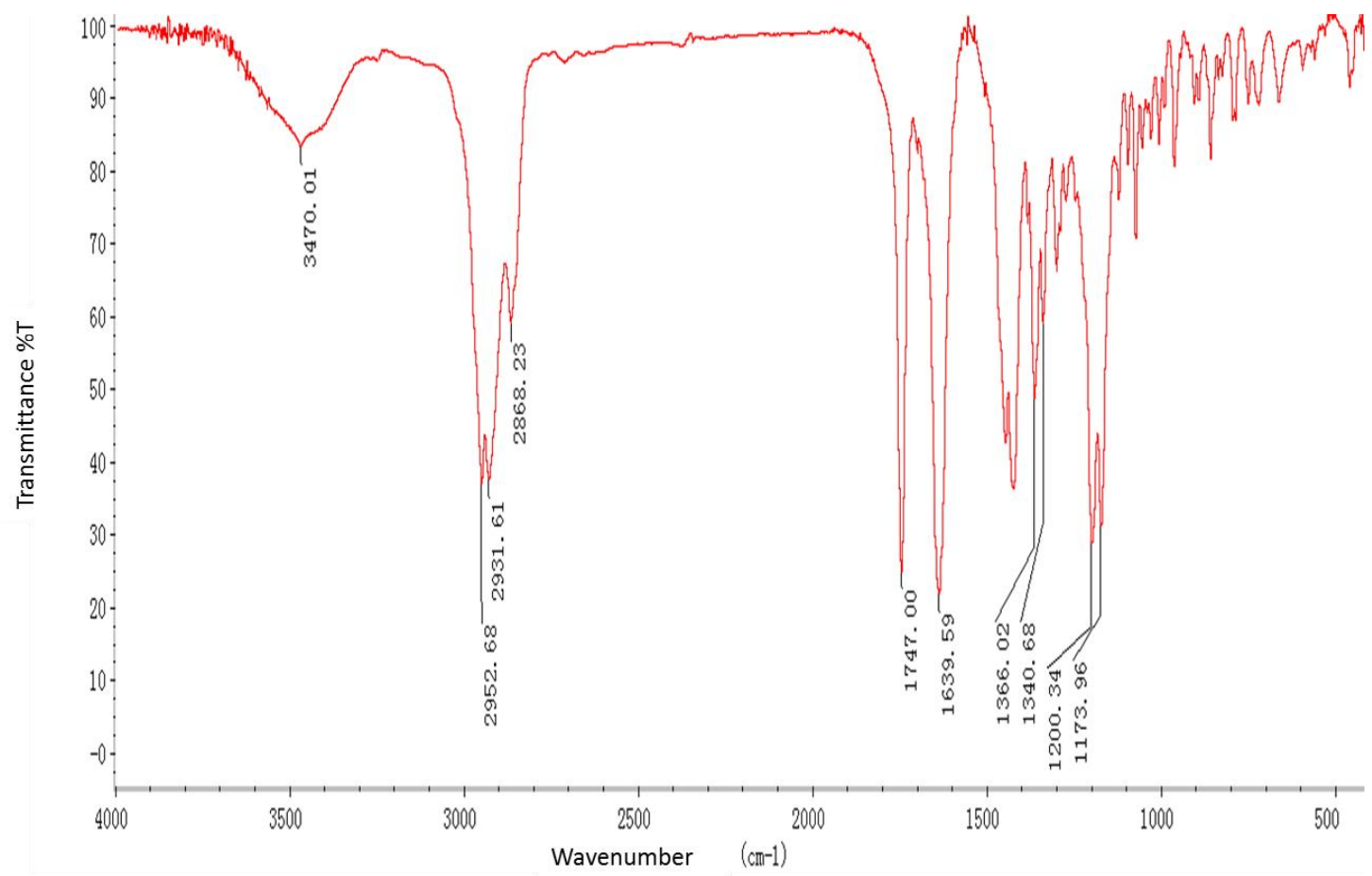


Sample: XWL-5

Date: $2020-06-02$

Method: C:\CHEM32\1\METHODS\CA.M

Injection Vol: $30 \mu \mathrm{L}$

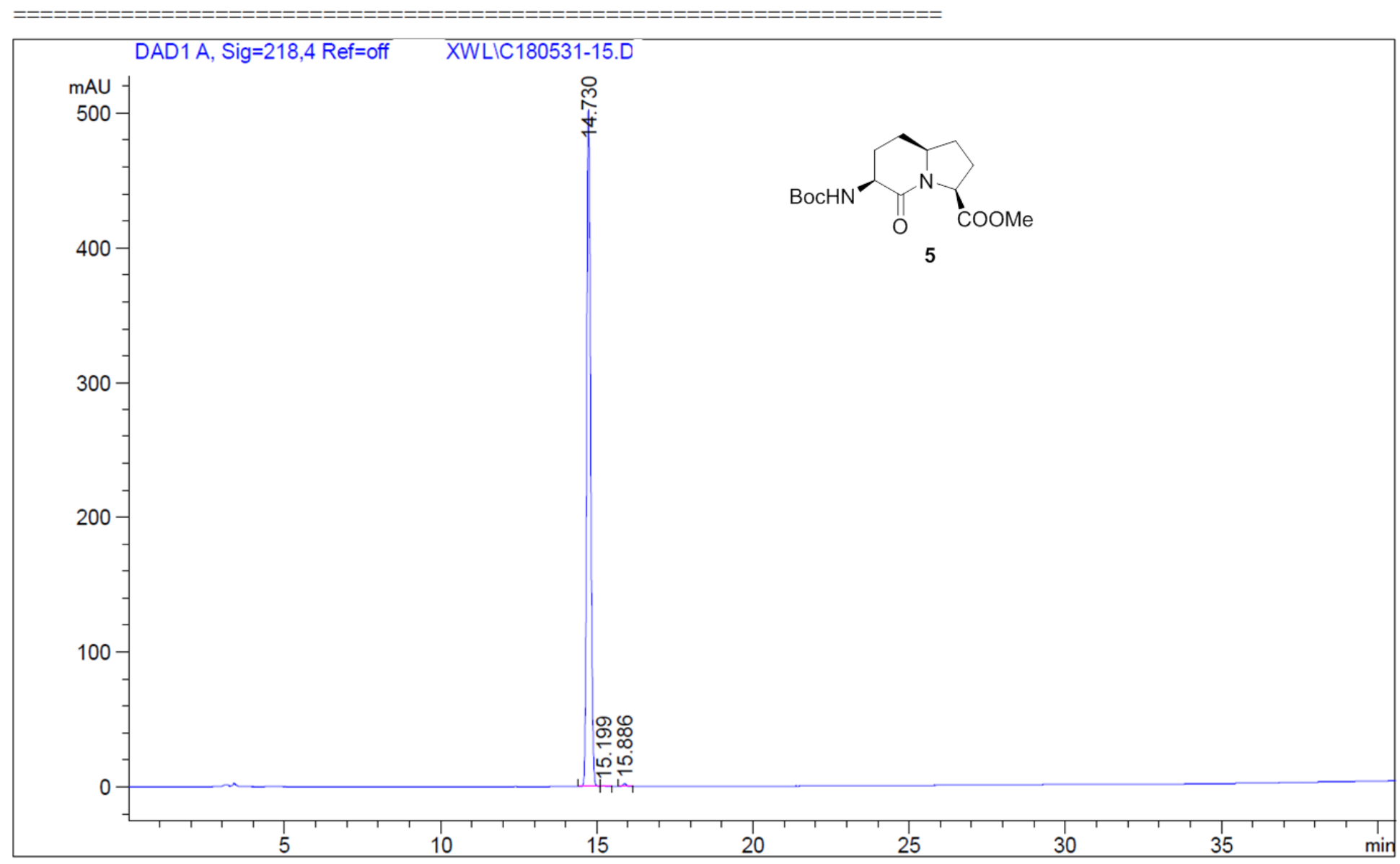

\begin{tabular}{|l|l|l|l|l|l|}
\hline Peak No. & $\begin{array}{l}\text { Retention Time } \\
\text { (Min) }\end{array}$ & Width (Min) & Area (mAU*s) & Height (mAU) & Peak Area (\%) \\
\hline 1 & 14.730 & 0.1421 & 4285.72146 & 502.75574 & 100 \\
\hline & & & & & \\
\hline
\end{tabular}


Sample: XWL-6

Date: $2020-06-02$

Method: C:\CHEM32\1\METHODS\CA.M

Injection Vol: $30 \mu \mathrm{L}$

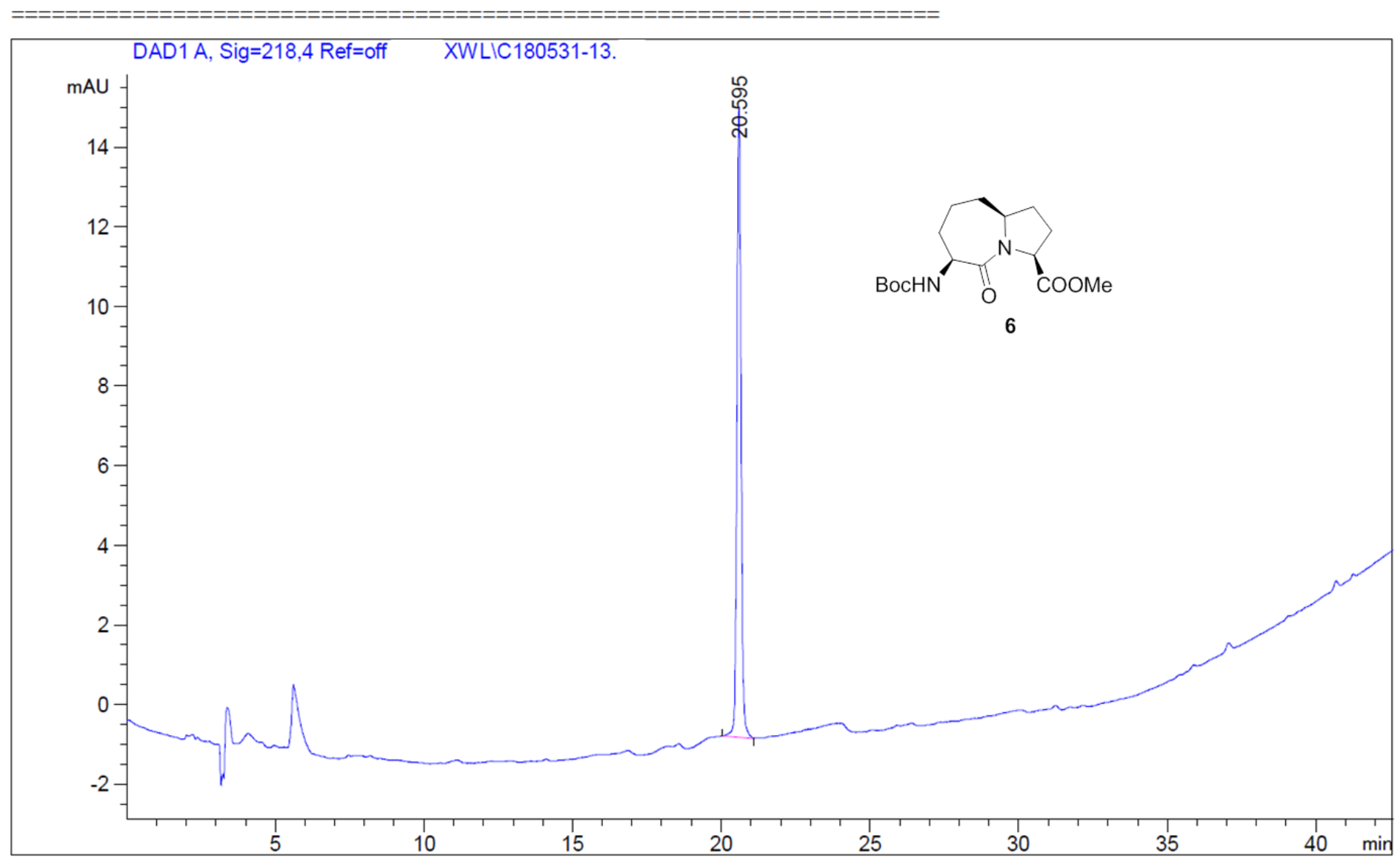

\begin{tabular}{|l|l|l|l|l|l|}
\hline Peak No. & $\begin{array}{l}\text { Retention Time } \\
\text { (Min) }\end{array}$ & Width (Min) & Area (mAU*s) & Height (mAU) & Peak Area (\%) \\
\hline 1 & 20.595 & 0.1496 & 153.73888 & 15.78537 & 100 \\
\hline & & & & & \\
\hline
\end{tabular}


Sample: XWL-21

Date: $2020-06-02$

Method: C:\CHEM32\1\METHODS\CA.M

Injection Vol: $30 \mu \mathrm{L}$

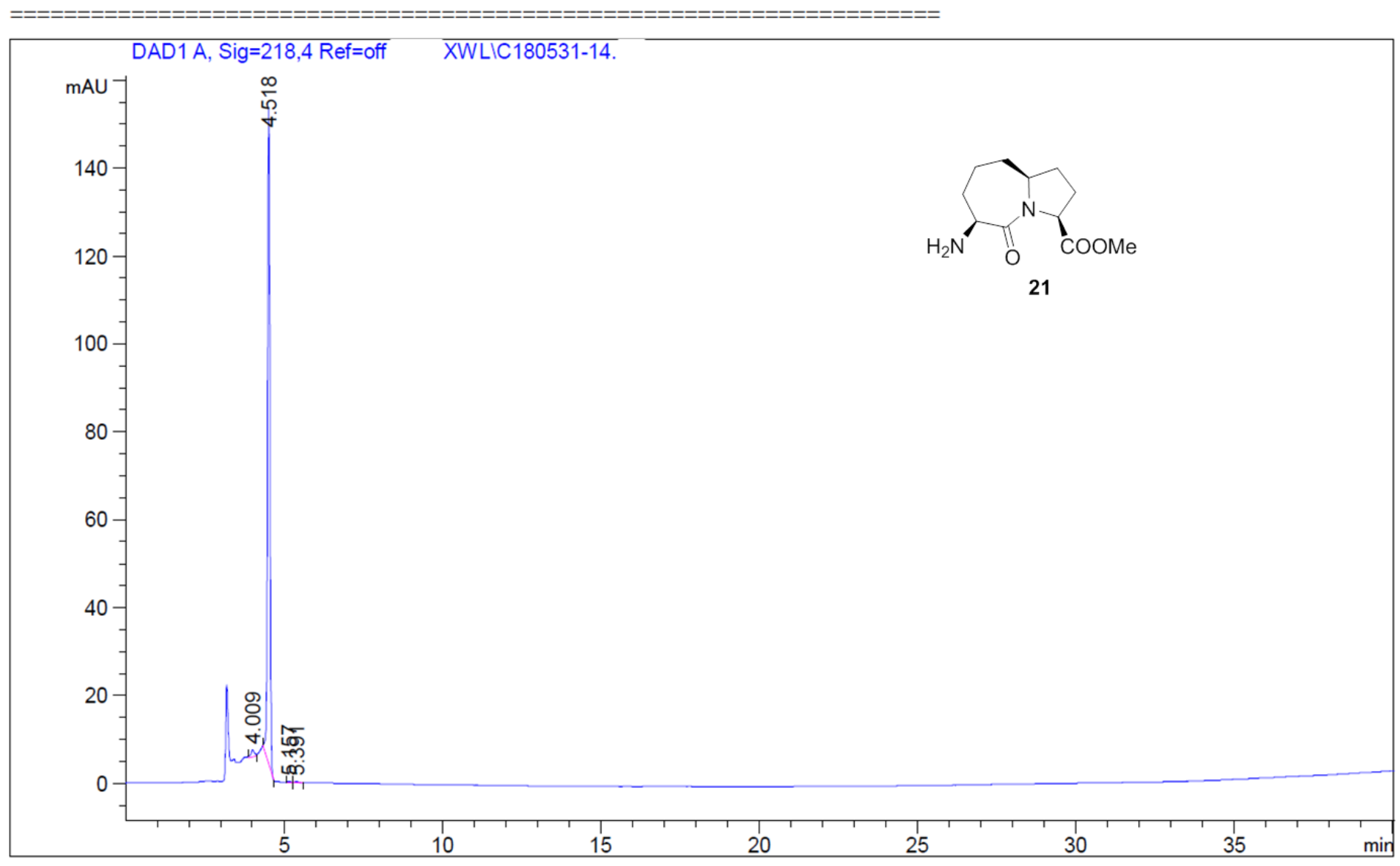

\begin{tabular}{|l|l|l|l|l|l|}
\hline Peak No. & $\begin{array}{l}\text { Retention Time } \\
\text { (Min) }\end{array}$ & Width (Min) & Area (mAU*s) & Height (mAU) & Peak Area (\%) \\
\hline 1 & 4.009 & 0.1278 & 12.50316 & 1.63048 & 1.5813 \\
\hline 2 & 4.518 & 0.0866 & 755.62079 & 149.35414 & 98.0930 \\
\hline 3 & 5.157 & 0.0836 & 1.07787 & $1.97621 \mathrm{e}-1$ & 0.1363 \\
\hline 4 & 5.391 & 0.0935 & 1.49722 & $2.51242 \mathrm{e}-1$ & 0.1894 \\
\hline
\end{tabular}


Sample: XWL-23a

Date: $2020-06-02$

Method: C: \CHEM32\1\METHODS\CA.M

Injection Vol: $30 \mu \mathrm{L}$

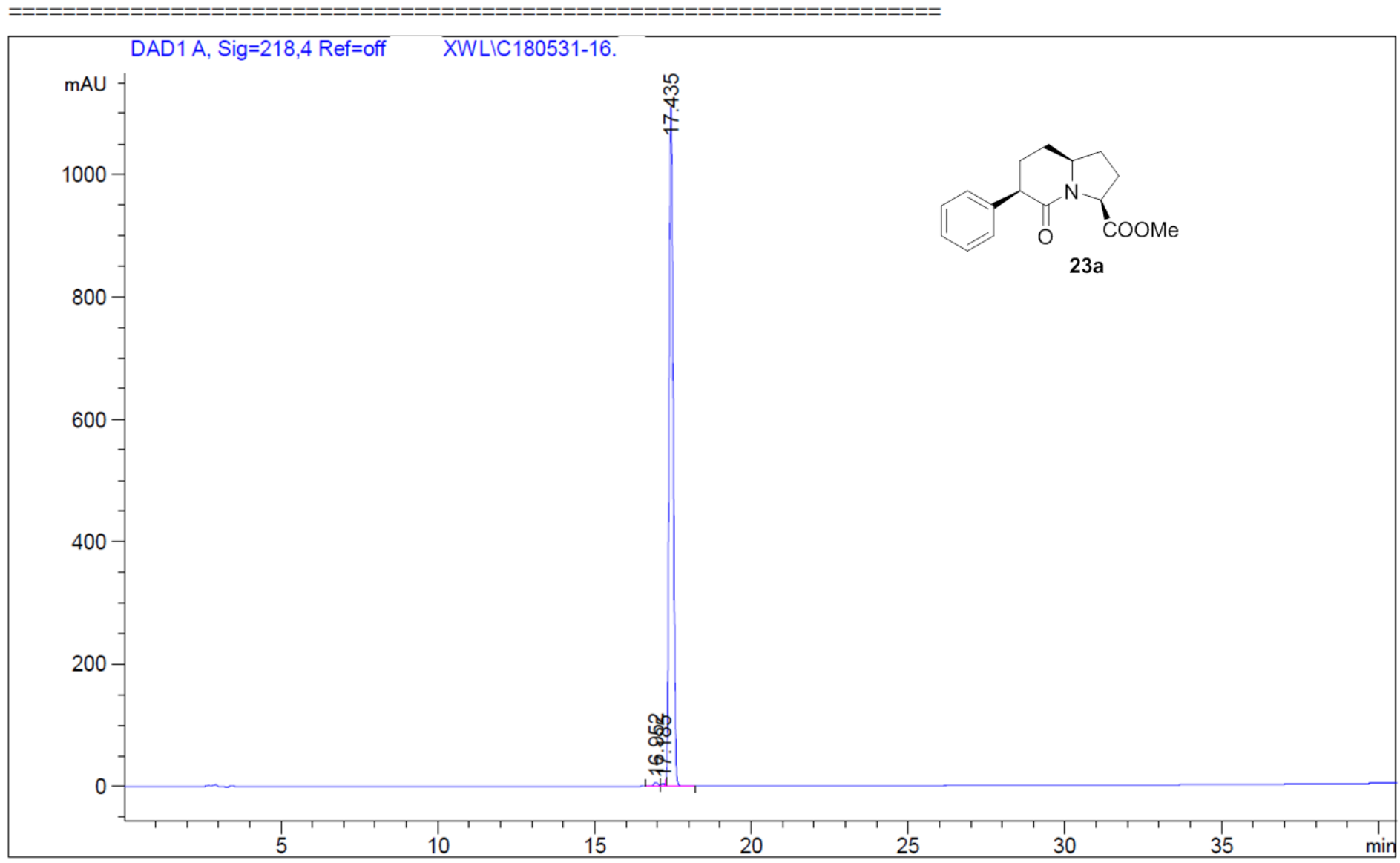

\begin{tabular}{|l|l|l|l|l|l|}
\hline Peak No. & $\begin{array}{l}\text { Retention Time } \\
(\text { Min) }\end{array}$ & Width (Min) & Area (mAU*s) & Height (mAU) & Peak Area (\%) \\
\hline 1 & 16.952 & 0.1409 & 55.91820 & 6.10216 & 0.5607 \\
\hline 2 & 17.185 & 0.1122 & 27.52199 & 3.64236 & 0.2760 \\
\hline 3 & 17.435 & 0.1420 & 9889.16406 & 1109.68774 & 99.1633 \\
\hline
\end{tabular}

